IZA DP No. 8342

Immigration, Naturalization, and the Future of Public Education

Ryuichi Tanaka

Lidia Farre

Francesc Ortega

July 2014 


\title{
Immigration, Naturalization, and the Future of Public Education
}

\author{
Ryuichi Tanaka \\ National Graduate Institute for Policy Studies
}

Lidia Farre

University of Barcelona, IAE-CSIC

and IZA
Francesc Ortega
Queens College, CUNY
and IZA

\section{Discussion Paper No. 8342 \\ July 2014}

IZA

P.O. Box 7240

53072 Bonn

Germany

Phone: +49-228-3894-0

Fax: +49-228-3894-180

E-mail: iza@iza.org

\begin{abstract}
Any opinions expressed here are those of the author(s) and not those of IZA. Research published in this series may include views on policy, but the institute itself takes no institutional policy positions. The IZA research network is committed to the IZA Guiding Principles of Research Integrity.

The Institute for the Study of Labor (IZA) in Bonn is a local and virtual international research center and a place of communication between science, politics and business. IZA is an independent nonprofit organization supported by Deutsche Post Foundation. The center is associated with the University of Bonn and offers a stimulating research environment through its international network, workshops and conferences, data service, project support, research visits and doctoral program. IZA engages in (i) original and internationally competitive research in all fields of labor economics, (ii) development of policy concepts, and (iii) dissemination of research results and concepts to the interested public.
\end{abstract}

IZA Discussion Papers often represent preliminary work and are circulated to encourage discussion. Citation of such a paper should account for its provisional character. A revised version may be available directly from the author. 


\section{ABSTRACT}

\section{Immigration, Naturalization, and the Future of Public Education *}

This paper analyzes the effects of immigration on the education system of the receiving country from a political economy perspective. Specifically, we extend the school-choice model by Epple and Romano (1996b) and Coen-Pirani (2011) by incorporating a subsidy to private schools, a distinguishing feature of Spain's education system. We calibrate the model to match key moments of Spain's economy and education system in year 2008, the end of a large episode of immigration. By means of simulations we evaluate the effects of immigration on the size and quality of Spain's public education. Our main findings are as follows. First, immigration will lead to a small increase in the size of public education in terms of enrollment. However, this increase in size masks an important composition effect. There is a large native flight away from public schools that is offset by the large inflow of immigrant children into public schools. Secondly, we predict a large reduction in the quality of public education, an 11 percent reduction in public spending per student. Our analysis suggests that these effects will unfold unevenly over time. While the changes in the size (and student composition) of public schools will take place promptly upon arrival of the immigrants, the reduction in funding will be more gradual and only fully take place once the immigrant population has been enfranchised. We also provide estimates separately for Spain's regions, which enjoy some autonomy in their education policies and experienced widely different levels of immigration.

JEL Classification: D7, F22, H52, H75, J61, I22, I24

Keywords: education, public school, immigration, naturalization

Corresponding author:

Francesc Ortega

Department of Economics

Queens College, CUNY

300A Powdermaker Hall

65-30 Kissena Blvd.

Queens, New York 11367

USA

E-mail: fortega@qc.cuny.edu

\footnotetext{
* We thank Daniele Coen-Pirani for comments and for making his code available for replication. We also benefitted from insightful comments by Antonio Cabrales, Kyle Hyndman, Max Steinhardt and seminar participants at CUNY, Tokyo and Tsukuba.
} 


\section{Introduction}

Public education is one of the pillars of modern democracies. Besides educating voters so that they can delegate policy-making to effective politicians, it has also been argued that public education plays an important economic role by helping rein in income inequality, facilitating upward mobility, and fostering economic growth. ${ }^{1}$

For these reasons ensuring sufficient funding for high-quality public education is a fundamental public policy in every country. From a political economy perspective, the key determinant of the quality of public education is the income distribution of voters and their preferences over public education. These preferences depend, in turn, on whether a household chooses to send their children to tuition-free public schools or to private ones (Epple and Romano (1996b)). As a result of this feedback between policies and individual choices, shocks to voters' preferences may propagate into unexpectedly large changes in the quality of public education.

Rapid demographic changes can operate as one such shock. Specifically, when a country experiences a large immigration wave its domestic politics are likely to be profoundly reshaped, with wide-ranging consequences for public policies and the welfare state. In particular, there are a number of ways in which immigration may affect education policies. On the one hand, immigrant households often lead to a disproportionately large increase in enrollment in public schools, given their relatively lower average income and higher fertility. This may lead native voters to change their preferences over the level of resources to devote to public education. On the other hand, immigrants eventually affect the politics of the host country either directly when they become naturalized (and gain the right to vote) or indirectly when forward-looking politicians cultivate their favor in anticipation of their enfranchisement. In an influential study of the effects of immigration on the education system, Coen-Pirani (2011) argues that the large immigration wave experienced by California between 1970 and 2000 may have been responsible for a $24 \%$ reduction in the quality of public education, measured by spending per student in public schools, and a reduction in the share of native students enrolled in public schools.

Naturally, the effects of immigration on the education system of the host country depend crucially on the characteristics of the immigrant population, such as their income (Dottori et al. (2013)) and their aspirations and attitudes toward education (Goyette and Xie (1999),

\footnotetext{
${ }^{1}$ See, for instance, Glomm and Ravikumar (1992), Galor and Zeira (1993), Fernandez and Rogerson (1996), Gradstein and Justman (2002), Blankenau et al. (2007), or Takii and Tanaka (2009), among many others.
} 
Hsin and Xie (2014)). Likewise some features of the education system in the host country may also mediate the effects of immigration on voters' support for public education. One such feature is the cost incurred by households that want to send their children to private schools. In some countries private schools charge very high tuition and can only be afforded by an affluent minority. For instance, average private school tuition in the U.S. in 2007-2008 was $\$ 8,549$ (18 percent of GDP per capita in that year). ${ }^{2}$ In other countries governments subsidize private schools, greatly reducing the tuition that households need to pay. For instance, the average annual private school tuition in Spain was below 500 euros (2 percent of GDP per capita). ${ }^{3}$

This paper studies both qualitatively and quantitatively how immigration affects the education system of the receiving countries. For this purpose, we focus on the recent experience of Spain, which experienced a large-scale immigration episode between the late 1990's and the late 2000's. In 1998 its foreign-born share among the working-age population was about 3 percent but rose by 10 percentage points over the course of a decade. Immigrants from a wide variety of countries were attracted to Spain because of its robust economic growth, which came to a halt in 2008 when the Great Recession and the subsequent austerity measures plunged the economy into a severe slump. In addition to its large magnitude, we also emphasize the importance of accounting for the large diversity of the immigrant population in Spain, both in terms of their earnings and preferences for education.

A defining feature of Spain's education system is a large role played by private schools, which account for one third of the overall enrollment in compulsory education. ${ }^{4}$ Underlying the high popularity of private schools among Spanish households is the large subsidy that most private schools receive from the government, which allows these schools to charge fairly low tuition. While not unique to Spain, the presence of a subsidy to private education has not been taken into account in previous analyses of the effects of immigration on the education system. Thus one contribution of our work is to examine how the presence of the subsidy affects the political economy of public education and the effects of a large

\footnotetext{
${ }^{2}$ Table 63 in the Digest of Education Statistics 2010, National Center for Education Statistics. Includes elementary, secondary and high school. On average the tuitions charged by elementary, secondary, and high schools were $\$ 6,733, \$ 10,549$, and $\$ 10,045$.

${ }^{3}$ In Spain in year 2007 average tuition in subsidized (concerted) schools was 260 euros and in fully private schools was 2,223 euros (Family Expenditure Survey), with wide regional variation. In that same year enrollment in the former was 88 percent of the combined enrollment in concerted and fully private schools (elementary and secondary education combined). As a result the average annual tuition in private schools (concerted or not) in Spain in 2007 was 476 euros.

${ }^{4}$ In the United States private schools account for only 10 percent of the overall enrollment in pre-university education.
} 
immigration wave.

More specifically, in this paper we build a political economy model of school choice $a$ la Epple and Romano (1996b). Following Coen-Pirani (2011) we adapt it to the analysis of immigration by allowing for a great deal of heterogeneity in households' preferences over education. In particular, we allow for heterogeneity within the immigrant population in order to capture the large differences in the school choices of Spanish immigrants on the basis of their country of origin. Furthermore we assume that private schools are subsidized by the government although they may also charge tuition. We then calibrate the model to match key moments of Spain's economy and education system in year 2008. In line with the Spanish experience we assume that immigrants had access to free public schools and subsidized private schools, and paid taxes, just like natives. However, they were not allowed to vote.

To evaluate the quantitative impact of immigration we simulate the model under two counterfactual scenarios. First, we simulate the economy under the assumption that the immigrant population in Spain had remained as in year 2000. By comparing the equilibrium outcomes to the benchmark for year 2008 this exercise identifies the effects of immigration arising from the increased demand for schooling by the immigrant households and their contribution to the public coffers through taxes. As we show, the arrival of immigrant households had an effect on the education policy preferred by the median voter. Second, we consider a counterfactual scenario where the immigrant population in year 2008 is naturalized. In this case we focus on the effects arising from the enfranchisement of immigrants. Since on average immigrants in Spain had lower income than natives, the median voter shifted down in the income distribution and this affected the policy supported by the majority of voters. To some extent one can view these two exercises as providing the short and long-run effects of immigration on the country's public education policy.

Our main findings are as follows. First, the combined effects of immigration and naturalization will lead to a small increase in the size of public education, with enrollment per 100 households increasing by about 0.63 . However, this increase in size masks an important composition effect. There is a large reduction in the enrollment of native students in public schools (who flee toward private schools). But this is offset by the arrival of a large number of immigrants into the economy, characterized by a much higher propensity than natives to attend public schools. In net terms the combined effect on native enrollment in public schools is a reduction in 3.5 students per 100 households. Hence, immigration is responsible for a combined increase in 4.1 public-school students per 100 households. 
Secondly, there will be a large reduction in the quality of public education. We estimate that public spending per student will fall by 11 percent reduction. Our analysis suggests that these effects will unfold unevenly over time. While the changes in the size (and student composition) of public schools will take place promptly, upon arrival of the immigrants, the reduction in funding will be more gradual and only fully take place once the immigrant population has been fully enfranchised.

We also recognize that regional governments in Spain have some degree of autonomy in deciding their education policies and that the size of the immigration flows, relative to population, varied widely across Spanish regions. Thus we also provide a regional analysis where we treat each of Spain's 17 regions as an economic unit determining its education policy autonomously and responding to the immigration inflow into the region. We find a great deal of heterogeneity in the effects of immigration across Spanish regions. In the regions with the largest immigration flows, relative to population, immigration may have led to a 25 percent reduction in public education spending per student, and a 7 percentage-point reduction in the share of native students enrolled in public schools.

Our analysis and calibration strategy are closely related to the above-mentioned study by Coen-Pirani (2011). Our theoretical model departs from his framework by explicitly considering multiple source countries for immigrants, allowing for group-level heterogeneity both in terms of income as well as preferences for education. As noted earlier, our framework also features a subsidy for private schooling, in line with the characteristics of Spain's education system. In terms of our focus, we emphasize the decomposition of the effects of immigration from those of naturalization, and we also investigate how immigration affects regional inequality in education policies.

More generally, this paper is related to studies that evaluate the effects of immigration on the size of government. Razin et al. (2002) argue that immigration is likely to lead to lower redistribution because of a 'fiscal leakage' effect. Along these lines, a recent empirical study by Speciale (2012) finds that immigration flows into European countries are associated with a reduction in public spending. Somewhat in opposition to these papers, the theoretical arguments in Ortega (2010) suggest that when voters are foresighted immigration may be key in order to sustain political support for income redistribution. The current paper focuses on a particular type of redistributive policy, public education, to see how immigration affects its quantity and quality. In this sense, our work is closely related to the large literature on education finance and its political economy (e.g., Fernandez and Rogerson (1995), Fernandez and Rogerson (1999)). 
Our work is also related to Dottori et al. (2013) who theoretically characterize optimal immigration policies that take into account the effects of immigration on the school choices of natives. Their main finding is that the optimal policy is highly biased in favor of skilled immigrants. A recent study by Albornoz-Crespo et al. (2011) presents a model of endogenous migration at the household level where school quality and student outcomes are determined endogenously. In their model the key dimension of heterogeneity is parental motivation toward their children's education and they analyze which immigration policies produce positive selection along this dimension. Our model also incorporates these dimensions of household heterogeneity, which play an important role in the quantitative evaluation of the impact of immigration on education policy.

The structure of the paper is as follows. Section 2 presents a concise description of the Spanish schooling system.In Section 3, we show summary statistics. Section 4 presents a simple theoretical framework based on the model by Epple and Romano (1996b). In Section 5 we explain our calibration strategy as well as the data for the calibration. Section 6 presents the results of the counterfactuals. Section 7 discusses regional variation of the impact of immigration on public education policy. Section 8 concludes.

\section{Institutional Background: the Spanish Education System}

Compulsory schooling in Spain is composed of two stages: six years of elementary (primary) school and four years of secondary schooling (known as E.S.O, or Compulsory Secondary Schooling in its Spanish acronym). As a result, students are required to be in school between the ages of 6 and $16 .^{5}$ Beyond compulsory schooling, pre-university education also includes two years of Bachillerato, which prepares students for college, or alternatively occupational training (Formacion Profesional).

Between years 2000 and 2009 public spending in education in Spain increased year after year. In 2009 the overall public spending in education was 52.5 billion $\left(10^{9}\right)$ euros, $4.98 \%$ of GDP. The largest share of these funds are devoted to pre-university education $(62.3 \%$ in year 2009). ${ }^{6}$ A large share of the budget is used to directly finance public schools, which are free of tuition. But a sizable amount is also devoted to subsidizing private elementary and secondary schools (5.9 billion euros in 2009, about 18 percent of the pre-university public spending). As a result of the affordable tuition, private schools account for a large share

\footnotetext{
${ }^{5}$ However, it is very common to begin school at age 3: in the academic year 2010-2011 the enrollment rate for 3-year olds was over 96 percent.

${ }^{6}$ Financing for public universities accounts for $20.7 \%$ of the budget. The source for this data is the report 'Datos y Cifras - Curso escolar 2011/2012' by the Ministry of Education.
} 
of the student body in Spain. In academic year 2009-2010, about $1 / 3$ of the pre-university students was enrolled in private schools. In comparison in the US the share of students in private schools is about 10 percent (National Center for Education Statistics, academic year 2009-2010).

The vast majority of private schools in Spain are subsidized by the government and are known as 'concerted' schools. ${ }^{7}$ In exchange for government funding that supposedly covers the school's whole salary bill, concerted schools agree to conduct an admission policy on the basis of the same criteria as public schools and to closely follow the core curriculum of public schools. Concerted schools account for almost 90 percent of the private-school enrollment. The remaining students attend private schools that are not subsidized and therefore charge much higher tuition.

While, in theory concerted schools are not allowed to charge for tuition, in practice there are quasi-compulsory payments required from parents in terms of donations to the parents' association, building maintenance or financing of extracurricular activities. According to a 2012 study by the Association of Spanish Consumers (OCU (2012)), over 90\% of concerted schools require payments that are perceived by households as compulsory. The average annual payment was 501 euros, much lower than the tuition charged by fully private schools. ${ }^{8}$

In practice there are important differences between public and private schools. First, some evidence points to better student outcomes in standardized tests in private schools, followed by private concerted schools, and last by public schools (Trillo del Pozo et al. (2006)). ${ }^{9}$ Second, the share of immigrant students in public schools is much higher than in private schools. In part this may be due to the larger out-of-pocket household expenses but it is also possible that the emphasis on Catholic education in concerted schools is an important deterrent for immigrant households with a different religious background. ${ }^{10}$

\footnotetext{
${ }^{7}$ Concerted schools were introduced in 1985 to accommodate the increasing demand for education that resulted from the baby boom and the increase in compulsory schooling age, and the majority are Catholic. For more details see Arellano and Zamarro (2007).

${ }^{8}$ In some neighborhoods in Barcelona and Madrid tuition in concerted schools can be as high as 200 euros per month. More systematic evidence is available in the 2007 supplement to the Family Expenditures Survey, which reported average annual household expenditures per student disaggregated by type of school. Focusing on expenditures in tuition (upfront or as monthly fees) and extracurricular activities taking place within the schools, the average expenses per student in compulsory secondary school in public, concerted, and private schools were, respectively, 10 euros, 260 euros, and 2,223 euros.

${ }^{9}$ What is less clear is whether the source of the differences is due to sorting in ability and family background or to the value-added provided by the schools. For instance, Calero and Escardibul (2007) and Anghel and Cabrales (2010) find that differences in performance between public and concerted schools are largely accounted for by parental background.

${ }^{10}$ de la Rica and Ortega (2012) report that 11 percent of the foreign-born population in Spain in year 2008 originated in Morocco. Adding also other immigrants from majority Muslim countries or followers of other religions leads to an important share of the immigrant population that may be disinclined to attend
} 
In summary, the main distinguishing feature of the Spanish compulsory education system is the large share of students in subsidized private schools. We will present a simple theoretical model in Section 4 capturing this important feature.

\section{Summary statistics}

Let us begin by illustrating the impact of immigration on the Spanish schooling system. Between year 2000 and 2010 the population of students with foreign nationality increased by a factor of 5.4, from 141,916 to over 770,384 students. ${ }^{11}$ The rise in this segment of the student population was very rapid until 2008 (when it reached 755,587 students) and has plateaued since then, reflecting the sharp reduction in immigration flows as the Great Recession hit the Spanish economy.

The impact of immigration on public and private schools has been very uneven. In year 2000 the share of foreign students in public and private schools was similar (2.3 and 1.4 percent, respectively). By 2008 the corresponding figures were 11.9 and 5.6 percent. ${ }^{12}$ That is, approximately a 10 percentage-point increase in public schools compared to barely 4 in private schools. It is also worth pointing out that the immigrant population in Spain is very diverse in terms of origin. In 2010 the breakdown of the foreign student population by origin was as follows: $40 \%$ originated from South and Central America, 29\% from the rest of Europe, $23 \%$ from Africa, and about 6\% from Asia. Among all of these students, the vast majority are in public schools $(82 \%)$, with the remainder being accounted for by concerted schools $(14 \%)$, and only $4 \%$ in fully private schools. In comparison, the breakdown for the overall student population, including native students, is approximately $68 \%, 27 \%$, and $5 \%$, respectively.

The inflows of immigrants may affect not only the size but also the quality of education. Between years 2000 and 2010, increasing government funding has led to a general reduction in student-teacher ratios, a commonly used proxy for the quality of education (16 percent). However, this quality improvement has been much more muted in high immigration regions. Farre et al. (2014) document that the reductions in student-teacher ratios have been much smaller in regions that have experienced a large increase in their foreign-born share over the decade. This is illustrated in (Figure 1).

We next present some of the main variables that our analysis will focus on. The data have

Catholic schools.

${ }^{11}$ These figures do not include students that have double nationality or second-generation immigrant children so it underestimates the impact of immigration on the schooling system in Spain.

${ }^{12}$ Source: Spanish Ministry of Education, Culture and Sports. 
been collected from numerous sources, combining administrative education data provided by the Ministry of Education with a variety of household-level surveys. Details on the data sources and on the construction of these variables are collected in Appendix A.

Table 1 provides some descriptive statistics for years 2000 and 2008. The latter is the key year used in the calibration of our model since it corresponds to the end of the wave of immigration received by Spain. ${ }^{13}$ Between years 2000 and 2008 Spain experienced robust economic growth, with real GDP increasing by 32 percent in this 8 -year period. ${ }^{14}$ This was the continuation of an economic expansion that had begun in the early 1990s. This economic bonanza, combined with troubled economies in some low-income countries with ties to Spain, led to a large immigration wave. Between 2000 and 2008 the working-age population in Spain increased by almost 15 percent, about 4 million individuals due to immigration. Between 2000 and 2008 the foreign-born share of the population increased by almost 10 percentage points, reaching 13.10 percent in year 2008.

In our paper households are the main unit of analysis. Between years 2000 and 2008, the number of households in Spain increased by almost 35 percent (3.3 million), with a large share of the increase being driven by immigration. In 2008 the Spanish economy had 12.7 million households and about 13.8 percent of all households where headed by a foreign-born individual. Besides its large size the immigration wave into Spain over most of the 2000s is characterized by its wide variation in terms of country of origin. It is helpful to subdivide the immigrant population in four groups according to the continent of origin. Between 2000 and 2008, the number of households headed by an immigrant from Europe increased from 1.38 to 5.09 percent of the overall number of households. Similarly, the number of immigrant households with American origin (North, South and Central) increased from less than 1 percent to 5.62 percent of all households in year 2008. There were also sizable increases in the numbers of households headed by Africans and Asians, reaching 2.62 and 0.48 percent of all households, respectively, in year 2008. In terms of countries of origin, Romania, Ecuador, Morocco and China are the main countries in each group (de la Rica and Ortega (2012)).

In year 2008 the average native household earned 29,403 euros. In comparison the average immigrant household earned 11 percent less (26,250 euros). ${ }^{15}$ However, this masks

\footnotetext{
${ }^{13}$ Between 2008 and 2013 the Spanish economy has suffered a severe recession that has led to net population outflows.

${ }^{14}$ In comparison nominal GDP increased by $73 \%$ thus, approximately, the price level increased by 39 percent between years 2000 and 2008 .

${ }^{15}$ The data for year 2000 cannot be disaggregated by nativity because the Family Expenditure Survey only identified immigrant households from year 2006 onward.
} 
substantial heterogeneity across immigrant groups in their socio-economic status. de la Rica and Ortega (2012) report that the share of the population (males, age 25-50) with at most primary schooling was $63 \%$ among Moroccans, $41 \%$ among Eastern Europeans, and $33 \%$ among Latinos, compared to just $18 \%$ among Spanish natives. Similarly, these groups report higher rates of early marriage for women compared to natives.

Not surprisingly, differences in socio-economic status are also mapped into differences in the share of students in each group attending public schools. As reported in Table 1, the share of native students enrolled in public schools in year 2008 was 65 percent, compared to 83 percent for immigrant children. Among these, the public school enrollment share ranged from 75 percent for Asian children to 90 percent for African children. It is also interesting to note that the overall increase in the share of students in public schools has increased by 3.5 percentage points between years 2000 and 2008, from 66.2 to 69.7 percent. Among natives the share of students enrolled in public schools actually fell by 1 percentage point in this period. Therefore the overall increase in the share of students in public schools is due to a composition effect: the large increase in immigrant children combined with their higher propensity to attend public schools. ${ }^{16}$

Let us now turn to public expenditure in education. Adding all education levels, public expenditure in education reached 4.58 percent of GDP in year 2008 (50.9 billion euros). This is a significant improvement since year 2000, when it was 4.35 percent of GDP, and leaves Spain just below the average of the European Union (27 member states) which was about 5 percent in year 2008. Given our focus on compulsory schooling, it is more relevant to report the spending that corresponds to pre-university education only in Table 1. Spending in pre-university education in year 2000 amounted to 2.70 percent of GDP, and increased to 2.93 percent in year 2008. Spending in subsidizing private schools, which is about 18 percent of all pre-university spending, also increased as a share of GDP over these years.

\section{The Model}

In this section, we extend the school choice model developed by Epple and Romano (1996b) along two dimensions. First, we introduce household heterogeneity in preferences for education. This was also a feature of the extension proposed by Coen-Pirani (2011), who allowed for parameter heterogeneity between natives and immigrants. We extend the model further by allowing for group-specific parameters within the immigrant population in order to

\footnotetext{
${ }^{16}$ In addition there has been an increase in the public school shares for all immigrant groups between years 2000 and 2008.
} 
accommodate the wide diversity of Spain's immigrant population.

Our second point of departure is that our framework includes a public subsidy to private schools, which is a defining feature of the Spanish education system. As we have seen in Section 2, the Spanish education system is characterized by high enrollment in private schools compared to other countries, driven by the highly subsidized tuition in most private schools. ${ }^{17}$

\subsection{Set up}

The economy is populated by a unit measure of households that differ in income (wealth) $y$, number of children $n$, country of origin $m$, and in their preference for education relative to consumption. Native households are indexed by $m=0$, and $m=1,2,3, \ldots, M$ denotes immigrant households from origin country $m$.

Households derive utility from consumption $c$ and from the per-child units of education received by their children, $E .^{18}$ Specifically, the utility function is given by:

$$
u(c, e, z, \lambda, m)=\frac{c^{\alpha}}{\alpha}+\gamma_{m} \lambda \frac{E^{\alpha}}{\alpha},
$$

where $\alpha<1, \gamma_{m}>0$, and $\lambda>0$. While $\gamma_{m}$ is a preference parameter for education that is common to all households from the same origin country, $\lambda$ allows for heterogeneity across households within the same origin group. These terms will allow us to match differences across groups in their educational investments over and above those induced by differences in household income.

There are two types of schools: public and private. All public schools are homogeneous in quality, that is, children attending any public school receive $e$ units of education. In contrast there is a range of private schools of varying quality. All private schools receive a per-student subsidy from the government, denoted by $b \geq 0$. In addition households pay tuition $z \geq 0$, which together with the subsidy determines the education units (quality) of private schools, given by $b+z$. We also assume that both natives and immigrants are eligible to send their children to tuition-free public schools and to subsidized private schools, in line with the institutional arrangements in Spain. Finally, we assume that public expenditure in education, which is the sum of direct expenditure on public schools and the subsidies to private education, is financed with a linear tax $s$ on household income $y$.

\footnotetext{
${ }^{17}$ As will become clear later, formally the subsidy to private education renders our model more similar to the so-called 'topping-on' education models, while Coen-Pirani (2011) and Epple and Romano (1996a) are 'opting-out' models of school choice.

${ }^{18} \mathrm{We}$ assume that all children in a household attend the same school.
} 
Conditional on sending children to public school, the household's indirect utility is given by:

$$
u(y(1-s), e, 0, \lambda, m)=\frac{(y(1-s))^{\alpha}}{\alpha}+\gamma_{m} \lambda \frac{e^{\alpha}}{\alpha},
$$

which is increasing in disposable income and in the quality of public education. We also note that the number of children in the household does not enter into the previous equation because households derive utility from the per-child units of education.

Conditional on private school, households choose their preferred school among a range of options indexed by the quality premium relative to public schools $z$. As a result, the household's indirect utility is given by:

$$
V(y(1-s), n, b, \lambda, m)=\max _{z \geq 0} \frac{\left[y(1-s)-p_{m} z n\right]^{\alpha}}{\alpha}+\gamma_{m} \lambda \frac{(b+z)^{\alpha}}{\alpha},
$$

where $p_{m} z$ is the tuition per student in group $m$. We refer to $p_{m}$ is an origin-specific 'price' of education. This parameter allows us to consider the possibility that because of, say, language barriers, children of a particular immigrant group may require a larger investment in order to acquire the same units of education as a native child in the same school. Within private schools this means that this child's parents have to spend more in order to provide their child with the same education units as a native child. ${ }^{19}$ Symmetrically, we assume that the same costs of education for each group $m$ apply to public schools as well. That is, there are no technological differences between public and private schools.

\subsection{School choices given policies}

The education policy in this economy is summarized by the tax rate used to finance public education expenditures $(s)$, the quality of public schools $(e)$, and the subsidy received by private schools $(b)$.

Inspection of equations (2) and (3) reveals that there exists an income threshold $\hat{y}(n, s, e, \lambda, m)$ above which households send their children to private school. This income threshold depends on the household's number of children $(n)$ and on it's preference for education relative to consumption $\left(\gamma_{m} \lambda\right)$. It is straightforward to derive an expression for this threshold:

$$
\hat{y}(n, s, e, \lambda, m) \equiv\left(\frac{\gamma_{m} \lambda}{p_{m} n}\right)^{\frac{1}{\alpha-1}} \frac{e}{1-s} .
$$

\footnotetext{
${ }^{19}$ We acknowledge that it is not entirely realistic to assume that schools charge different tuition to different groups of students. However, we follow Coen-Pirani (2011) and make this assumption on the basis of its convenience. At any rate, our baseline model will assume that $p_{m}=1$ for all $m$.
} 
Intuitively, this threshold is increasing in the quality of public education $(e)$ and in the tax rate $(s)$. Note also that under the assumption of $\alpha<0$, which is the empirically relevant range, the threshold is increasing in the number of children in the household $(n)$ and the price of education $\left(p_{m}\right)$, and decreasing in the household's taste for education relative to consumption $\left(\gamma_{m} \lambda\right)$.

Conditional on choosing a private school, the utility-maximizing school chosen by the household is given by:

$$
z(y(1-s), n, \lambda, m)=\frac{y(1-s)-\left(\frac{\gamma_{m} \lambda}{p_{m} n}\right)^{\frac{1}{\alpha-1}}}{\left(\frac{\gamma_{m} \lambda}{p_{m} n}\right)^{\frac{1}{\alpha-1}}+p_{m} n},
$$

provided $y>\hat{y}(n, s, e, \lambda, m)$. Thus households with higher (disposable) income or a higher taste for education will choose better private schools. In contrast, households with more children or facing a higher 'price' of education will choose relatively worse (but cheaper) private schools. ${ }^{20}$

Let $f(y, n, \lambda, m)$ denote the joint density of income, number of children, idiosyncratic preference for education, and country of origin. For a given public education policy $(s, e)$, the number of students (enrollment) in public schools from households with origin $m$ can be computed by:

$$
n_{m}^{p u b}=\sum_{n} \int_{0}^{\infty} \int_{0}^{\hat{y}(n, s, e, \lambda, m)} n f(y, n, \lambda, m) d \lambda d y .
$$

for $m=0,1,2, \ldots$.

Consequently, the enrollment in private schools from households with origin $m$ is $\left(n_{m}-n_{m}^{p u b}\right)$, where $n_{m}$ is the total number of children from origin $m$. Naturally, if we let $h(n, m)=$ $\int_{y} \int_{\lambda} f(y, n, \lambda, m) d y d \lambda$ denote the joint density of $n$ and $m$, we can compute the total number of children in each group by $n_{m}=\sum_{n} n h(n, m)$.

Let us now describe the government's budget constraint:

$$
e \sum_{m} p_{m} n_{m}^{p u b}+b \sum_{m} p_{m}\left(n_{m}-n_{m}^{p u b}\right)=s \bar{y}
$$

where $\bar{y}$ is the average (and total) household income and, thus, the right-hand side is the tax revenue. The left-hand side contains the two entries in the government's education budget. The first term is the direct expenditure needed to finance public schools with quality level $e$. The second term is the cost of subsidizing students in private schools at a rate $b$ per

\footnotetext{
${ }^{20}$ Hereafter, we call a school private if it has strictly positive tuition $(z>0)$.
} 
student. Symmetrically to private schools, we allow for differences in the cost of educating children across the different groups $\left(p_{m}\right)$. Of course, we can always focus on scenario $p_{m}=p$ where the cost of educating children is the same across all groups.

As noted earlier, an education policy consists of three variables, $(s, e, b)$. One of these variables is pinned down by the government's budget constraint. Yet it is still the case that the voting problem (described below) is intractable without further restrictions. In order to make progress we link the level of the subsidy to the quality of public education. In particular, we assume that the (private education) subsidy per student is set at the same level as the spending in public education per student: $b=e .^{21}$ One implication of this assumption is that we are ruling out non-subsidized private schools. However, this type of schools accounts only for about 5 percent of the student population in Spain. Regarding the level of the subsidy, equal to the spending per student in public schools, we believe this feature to be rather realistic in the context of Spain where many private schools are heavily subsidized and set tuition to almost zero. ${ }^{22}$

\subsection{Majority-vote equilibrium}

Public education policy is determined by majority voting. ${ }^{23}$ In our baseline model we assume that only natives vote, but both natives and immigrants pay taxes and are eligible to enroll in free public school and to receive the subsidy for private education. ${ }^{24}$ We define a majority voting equilibrium in a standard fashion.

Definition: $\left(s^{*}, e^{*}, z^{*}\left(y\left(1-s^{*}\right), n, \lambda, m\right), n_{m}^{*}\right)$ is a majority-voting equilibrium if (i) $z^{*}\left(y\left(1-s^{*}\right), n, \lambda, m\right)$ is chosen optimally; (ii) the government budget constraint (7) is satisfied; (iii) the number of students in public schools for each groups is given by equation (6); and (iv) the equilibrium tax rate and education services per student $\left(s^{*}, e^{*}\right)$ are preferred by at least 50 percent of the voters (natives) to any alternative feasible policy in any pairwise comparison.

\footnotetext{
${ }^{21}$ More generally, we could consider that $b=\phi e$, where $\phi \leq 1$.

${ }^{22}$ In some provinces in Spain the average annual tuition charged by private schools is well below 200 euros (OCU (2012)), indicating that these schools are almost completely financed by the government.

${ }^{23}$ Since the subsidy is tied to the expenditure per student in public schools, $b=e$, we can omit it from the formal definition of equilibrium. Thus we are left with a two-dimensional policy but one of the variables is pinned down by the government's budget constraint. Thus a voting equilibrium will exist under some regularity conditions.

${ }^{24}$ The extension where we assume that immigrants are naturalized and gain the right to vote is straightforward.
} 
It is relatively easy to characterize the preferred tax rate for each household. Let us consider first households with children in a high income bracket. It can be shown that for households with income $y>y^{+}(n, m) \equiv \frac{p_{m} n}{\sum_{m} p_{m} n_{m}} \bar{y}$, the preferred tax rate is zero. ${ }^{25}$ This is not surprising since these individuals do not use public schools. They would prefer a world with zero taxes where they pay for their children's education purely through tuition since a positive tax rate implicitly redistributes income away from these households. Because of their high income and their choice of expensive private schools, when the tax rate is positive they end up paying more in taxes than what they receive through the subsidy.

Let us now turn to households with children but whose income is below $y^{+}(n, m)$. For a given public education policy, some of these households send their children to public schools (those with relatively lower income) while others send their children to private schools. However, when they form their political preferences, they all internalize the effect of their vote on the education policy and choose a strictly positive tax rate that maximizes the indirect utility from public school. The intuition is that these households are relatively poor and therefore optimally choose a tax that allows them to redistribute income from the wealthier households and in their own benefit through the school subsidy. For these households, the preferred tax rate is given by

$$
\hat{s}(y, \lambda)=\left[1+\left(\gamma_{0} \lambda\right)^{\frac{1}{\alpha-1}}\left[\sum_{m} p_{m} n_{m} y / \bar{y}\right]^{\frac{\alpha}{1-\alpha}}\right]^{-1} .
$$

Several points are worth noting. First, the only $\gamma_{m}$ term that appears in the equation is for $m=0$ because only natives are allowed to vote. Second, the preferred tax rate only varies across voters as a function of income $y$ and the idiosyncratic preference parameter for education $\lambda$. In our calibration, parameter $\alpha$ will be negative. Under this restriction, individuals with higher income (up to threshold $y^{+}(n, m)$ ) or with a higher individual preference for education will support a higher tax rate. As income rises households demand higher education levels for their children since here education is a normal good. Their voting power is used to raise higher tax revenue to be devoted to education, directly in terms of better funded public schools or through a larger subsidy for private education. Third, the preferred tax rate does not depend on the number of children. The reason is that voters with income below threshold $y^{+}(n, m)$ prefer the tax rate that maximizes the utility from public school and, hence, their out-of-pocket educational expenses do not vary with the

\footnotetext{
${ }^{25}$ Note that this income threshold only depends on the number of children, on average household income, and on the specific group $m$. All of these are exogenous parameters, unlike the earlier income threshold in equation (4) that depended on an arbitrary education policy.
} 
number of children. ${ }^{26}$

Let us now turn to households without children. As is typically the case in the data, this group is a majority among voters. Since these voters do not derive utility from education in our model the majority-vote tax rate will trivially be equal to zero. To address this issue we assume that the political preferences of childless households are the same as those with households with one child at the same level of income. The idea is that households without school-age children care about public education in the real world for a variety of reasons. For instance, because their unborn children or their grandchildren may attend public schools in the future. ${ }^{27}$

We can characterize the equilibrium education policy further. By solving equation (8) for household income, we obtain the income of the household that prefers that particular tax rate:

$$
y^{*}(\hat{s} ; \lambda)=\frac{1-\hat{s}}{\hat{s}}\left(\gamma_{0} \lambda\right)^{\frac{1}{\alpha}} \frac{\bar{y}}{\sum_{m} p_{m} n_{m}} .
$$

As noted earlier, under the assumption of a negative $\alpha$, there is a monotone increasing relationship between a household's income and its preferred tax rate (provided $\left.y \leq y^{+}(n, m)\right)$. Thus we can compute the number of native households who prefer a tax rate lower than a given $\hat{s}$ by

$$
\underline{n}_{0}(\hat{s})=\sum_{n} \int_{0}^{\infty}\left(\int_{0}^{y^{*}(\hat{s} ; \lambda)} f(y, n, \lambda, 0) d y+\int_{y^{+}(n, 0)} f(y, n, \lambda, 0) d y\right) d \lambda .
$$

The first term inside the parenthesis accounts for the households with relatively low income (public school users) whose preferred tax rate is below $\hat{s}$. The second term computes the number of households whose income is high enough that their preferred tax rate is exactly zero. This coalition was referred to as the ends against the middle by Epple and Romano (1996b) because the lowest tax rates are preferred by the households at both extremes of the income distribution.

Similarly, we can also compute the number of native households who prefer a tax rate above $\hat{s}$ :

$$
\bar{n}_{0}(\hat{s})=\sum_{n} \int_{0}^{\infty} \int_{y^{*}(\hat{s} ; \lambda)}^{y^{+}(n, 0)} f(y, n, \lambda, 0) d y d \lambda .
$$

The majority-vote equilibrium tax rate must satisfy $\underline{n}_{0}\left(s^{*}\right)=\bar{n}_{0}\left(s^{*}\right)$. That is, the equilibrium tax rate $s^{*}$ exactly balances the number of households who prefer a higher tax

\footnotetext{
${ }^{26}$ Our analysis has abstracted from other educational expenses such as textbooks.

${ }^{27}$ Political support for public education for childless households can also be argued on the basis of external effects associated with a more educated population such as lower crime, positive productivity spillovers, or a better informed electorate. See Coen-Pirani (2011) for further discussion on this assumption.
} 
rate with those who prefer a lower tax rate. As discussed in Epple and Romano (1996b), for some parameter configurations this model may feature multiple equilibria. However, given a set of parameter values, it is possible to verify the existence and uniqueness of a majority voting equilibrium numerically. We shall do so for our calibrated model.

\subsection{Comparative statics}

Before turning to our quantitative analysis we conduct two comparative statics exercises that will provide the intuition for the analysis in the remainder of the paper. Let us begin by considering the effects of an inflow of immigrants characterized by lower average income than natives. In line with our previous assumptions, these immigrants have the right to enroll their children in public schools and in subsidized private schools, and pay income taxes just like natives. However, these immigrants do not have the right to vote. Clearly, when these immigrants join the economy average household income falls. As a result, given the tax rate, public spending in education per child falls because of a tax-base effect: the increased spending due to the schooling of the immigrant children is lower than their contribution in terms of tax revenue. As seen in equation (8), when $\alpha$ is negative, the lower average income will lead to a higher preferred tax rate. Intuitively, (native) voters partly offset the reduction in public spending in education by raising the tax rate. ${ }^{28}$ It can be shown that the increase in the tax rate only partially mitigates the reduction in the quality of public education. The intuition for why immigration would lead to a reduction in the funding of public schools is similar to the fiscal leakage in Razin et al. (2002). Voters reduce the degree of tax-based income redistribution because part of the benefits now 'leak' to the immigrant population. ${ }^{29}$ Naturally, the lower quality of public education lowers the income threshold for using private schools and triggers a shift from public to private schools.

Let us now turn to the effects of naturalization of the immigrant population already in the country. Because of their lower average income, when immigrants gain the right to vote the median voter will typically move down along the income distribution. Again by virtue of equation (8), we can conclude that the majority-vote equilibrium tax rate will fall. Even though the tax rate moves in the opposite direction than in the previous comparative

\footnotetext{
${ }^{28}$ Even though immigrants cannot vote, the identity of the median voter is affected by immigration. Because immigration lowers average income then threshold $y^{+}$falls. This will increase the number of voters who prefer a tax rate below a given value, as seen in equation (10), and this will affect the income level of the median voter and her preferred tax rate.

${ }^{29}$ In their paper the tax rate finances a redistributive transfer. In addition immigrants are poor and can vote. Even though immigrants support higher redistribution, the median voter chooses to reduce the degree of income redistribution because of the leakage.
} 
statics exercise, it is also the case that the quality of public education (public spending per student) is reduced.

It is perhaps a bit puzzling that an increase in the share of lower-income voters leads to a lower tax rate. Here is the intuition. Clearly, the median voter will now have lower income because of the naturalization or relatively low income immigrants. Given the negative value for $\alpha$, a poorer median voter prefers a lower tax rate. The reason is that despite wanting better quality public schools, she internalizes the higher cost. Because of her lower income she cannot afford the prior level of taxes and, thus, chooses to reduce the tax rate. ${ }^{30}$

\section{Empirical Implementation}

\subsection{Calibration strategy}

The model is calibrated to Spain in year 2008. The reason we pick this year is that it marks the end of the recent immigration wave in Spain and the beginning of the Great Recession and the ensuing economic distress. Our baseline model assumes that private schools receive a subsidy per student equal to the spending per student in public schools. It also assumes that educating one immigrant child (of any group) has the same cost as educating a native child. This is a conservative choice that will lead to more muted effects of immigration on the quality of public education. We also provide several other calibrations where we vary these assumptions.

To calibrate the model we need to specify the values of the time-invariant parameters and the joint density $f^{t}(y, n, m, \lambda)$, which varies across years. We follow the calibration strategy proposed by Coen-Pirani (2011). Specifically, to calibrate the density $f^{t}(y, n, \lambda, m)$ we assume that the taste parameter $\lambda$ is independent of $(y, n, m)$ in the population. The distribution of $\lambda$ is taken to be lognormal with constant parameters $\left(\mu_{\lambda}, \sigma_{\lambda}\right)$. The parameter $\mu_{\lambda}$ is set at $-\sigma_{\lambda}^{2} / 2$ so as to deliver a mean value for $\lambda$ equal one. The joint distribution of $(y, n, m)$ in year $t$ can be decomposed as:

$$
g^{t}(y \mid n, m) h^{t}(n, m)
$$

where $h^{t}(n, m)$ is the joint density of $(n, m)$. The conditional density $g^{t}(y \mid n, m)$ is assumed to be lognormal with parameters $\mu_{y}^{t}(n, m)$ and $\sigma_{y}^{t}(n, m)$. The latter are estimated for

\footnotetext{
${ }^{30}$ This result depends, to some extent, on the tax instruments that are considered in the Epple and Romano economy. If lump-sum taxes or more progressive tax schedules were allowed, the median voter would probably be able to extract more from the wealthier households. Using data for Swedish municipalities Vernby (2013) found that enfranchising non citizens led to higher social spending.
} 
year 2008 by matching the conditional mean $E[y \mid n, m]$ and variance $V[y \mid n, m]$ of household income in the data for that same year.

Immigration status $(m)$ takes five possible values according to whether the household head is native $(m=0)$ or foreign-born $(m=1,2,3,4)$. Specifically, it takes the value of 1 for immigrants from European countries, 2 for those from Africa, 3 for America (North, Central or South), and 4 for Asia and Oceania. The number of children in a household $(n)$ is assumed to take four possible values: $0,1,2$, and $3+$, where $3+$ equals the average number of children in households with at least 3 children in the data. Density $h^{t}(n, m)$ is estimated non-parametrically using the frequency count of each cell $(n, m)$ in the data.

The cost of education for a native household $p_{0}$ is normalized to one without loss of generality. The relative cost of education for an immigrant child is set conservatively to be equal to that of natives, namely $p_{1}=p_{2}=p_{3}=p_{4}=1$, in the benchmark case. However, we will also consider scenarios where the cost of education for immigrants is higher than that for natives since it is often the case that remedial classes or extra help in the form of language instruction is provided to recently arrived immigrant children. ${ }^{31}$

We calibrate the seven parameters $\left(\alpha, \gamma_{0}, \gamma_{1}, \gamma_{2}, \gamma_{3}, \gamma_{4}, \sigma_{\lambda}\right)$ to match seven moments in the data. The first five moments are the number of native $(m=0)$ and immigrant children $(m=1,2,3,4)$ enrolled in public schools in year 2008. Note that matching these moments implies that the model will also exactly match the enrollment of each group in private schools as well as the share of each group that attends public schools. ${ }^{32}$ These are important moments since the data shows a large disparity in the share of children in each group attending public school, ranging from 65 percent (natives) to 90 percent (African immigrants), as documented in Table 3 (column 1, bottom panel). ${ }^{33}$ The sixth targeted moment is the share of aggregate income spent by the government to fund compulsory education, which includes both the direct funding of public schools as well as the subsidy to private schools. This value is directly related to the tax rate determined endogenously in the model and we refer to it as the implicit (education) tax rate. The seventh moment is the ratio between the average incomes of households with children in public and private schools in 2008 .

While the seven-equation system is highly non-linear, let us try to provide some intuition on which are the key parameters involved in attaining this calibration targets. For the

\footnotetext{
${ }^{31}$ For example, Coen-Pirani (2011) sets the cost of education for immigrant children in California to be four percent above that for native children.

${ }^{32}$ Recall that we consider compulsory education. Thus we do not allow for children to be out of school.

${ }^{33}$ The number of students in public schools for each group $m$ is estimated using the total number of children and the actual share of public school students for each group $m$. See Section A.3 for the detail.
} 
enrollment in public school for each group, the key parameter is $\gamma_{m}$, the group-specific parameter governing the taste for education relative to consumption. Higher values of $\gamma_{m}$ are associated with a higher willingness to spend on education and thus lower public school attendance for children belonging to group $m$. Parameter $\sigma_{\lambda}$ determines the degree of income mixing in private schools, with higher levels of $\sigma_{\lambda}$ associated with a higher ratio of average household income in public relative to private schools, namely, a lower degree of income segregation in schools. Finally, parameter $\alpha$ is crucial to determine the share of aggregate income devoted to education by the government, that is, the implicit tax rate because it determines the tax elasticity of the demand for education services.

\subsection{Calibration results}

Let us begin by presenting the 7 target data moments. These are reported in Table 3, column 1 (top panel). ${ }^{34}$ The implicit education tax rate in the data is 5.93 percent. We calculate this by computing the overall public spending in compulsory education (including the subsidy to private schools) in year 2008 and dividing by household income in that same year. This is a reasonably good approximation to the tax rate in our model, which is used exclusively to finance education. The next five moments are the number of public school students (per 100 households) that belong to each group $m=0,1, \ldots, 4$. Obviously, these figures are a function both of the absolute size of each group as well as of the group's preference for public schools. ${ }^{35}$ Finally, we also target the relative income of households that use public school relative to those that use private school, which is 0.73 . The second column in the table reports the same 7 moments in our calibrated model, which we are able to match with a high degree of accuracy.

We next comment on the specific values of the parameters that result from our moment matching exercise. Table 2 reports the calibration parameters. The first column presents the calibrated values in our main specification, where private schools receive a subsidy equal to the spending per student in public schools and we assume that the cost of educating immigrant children is the same as that of educating native children. The calibrated value of the parameter $\alpha$ is -0.87 , which is negative (as anticipated) and in line with existing empirical estimates. $^{36}$ The table also reports the calibrated parameters that govern the distribution

\footnotetext{
${ }^{34}$ The public school students per 100 households (24.88) is not a targeted moment. We target the analogous moments for natives and the four immigrant groups, which can be added to obtain the overall 24.88.

${ }^{35}$ The bottom panel in the table reports the share of the students in each group that attends public schools. These shares are perfectly matched when the number of public school students for each group is matched.

${ }^{36}$ The price-elasticity (in absolute value) implied by this value of $\alpha$ is 0.53 , only slightly higher than the range $(0.25,0.50)$ reported by Bergstrom et al. (1982) in their survey of the literature, and smaller than the
} 
of household preference shocks for education (relative to consumption), which we denoted by $\lambda$. More importantly, the table also reports the values for the coefficients that govern the group-specific taste for education, $\gamma_{m}$. The lower values for these parameters relative to $\gamma_{0}$ imply that immigrant households have a smaller preference parameter for education (relative to consumption) than native households. This is an implication of the fact that immigrant households are less likely to have children in private school conditional on income and family size. The calibration procedure then accounts for the observed enrollment of immigrant children in public school by selecting a value for $\gamma_{m}$ for $m=1,2,3,4$ smaller than the corresponding one for $\gamma_{0}$. For native households $\gamma_{0}=0.52$. Among immigrant groups the highest value is for Asians, with $\gamma_{4}=0.39$ and the lowest is for Africans $\left(\gamma_{2}=0.12\right) .{ }^{37}$

Columns 2 and 3 in the Table report alternative calibration specifications. In column 2 we report the parameter vector that matches the seven target moments when we assume that the cost of educating one immigrant child is 10 percent higher than the cost of educating one native child. ${ }^{38}$ The values of the parameters are very similar to those presented in the first column. Column 3 considers an alternative version of the model where private schools are not subsidized at all. In this case, households choose between public schools and private ones that are fully financed through tuition. This corresponds to the so-called opting-out model of school choice, which was the basis for the analysis in Coen-Pirani (2011). This version of the model provides an important robustness check since it is informative regarding how sensitive our results may be to changing the size of the subsidy to private education. The parameter values are not directly comparable to those in columns 1 and 2. However, the equilibrium outcomes remain comparable to those in the baseline model. ${ }^{39}$

We now turn to evaluate the performance of our calibrated model. The credibility of the counterfactual analysis in the next section crucially depends on the ability of the model to match the target moments as well as some other relevant moments that have not been used

value implied by Fernandez and Rogerson (1998)'s calibration for California.

${ }^{37}$ We note that in reality many of the subsidized private schools are Catholic. This may explain why some immigrant groups are less inclined to send their children to these schools, which may reflect in a lower overall preference for education relative to consumption.

${ }^{38}$ In this case the number of education units received by immigrant children, which is what enters the utility function of the household, will differ from education spending per student. This was not the case for our main specification (column 1) because there we assumed an equal education cost for natives and immigrants (and normalized that cost to be one).

${ }^{39}$ In the opting-out model, the preference parameter $\lambda$ is not the preference for education in general but for private education specifically as in Coen-Pirani (2011). Additionally, the implicit tax rate used in calibration is calculated so that public school spending per student is 4,582 euros, the same level as in the benchmark model. The implicit tax rate in the opting-out model is much lower than one in our benchmark model because taxes only need to finance the direct spending on public schools since there is no subsidy to private education. 
as calibration targets. As noted already, we are able to perfectly solve for the 7-equation system, namely, we find values for the 7 parameters that allow us to match with high accuracy the 7 target moments, as can be seen in columns 1 and 2 in Table 3. We now propose a more relevant validation exercise. We compute the equilibrium maintaining the values for the 7 key parameters but replacing the 2008 data for the distributions of income (conditional on number of children and group) and of the number of children and group for the corresponding values in year 2000, namely, $g^{2000}(y \mid n, m), h^{2000}(n, m)$. We then compare the resulting equilibrium predictions to data for the 7 key moments of our model. ${ }^{40}$

Columns 3 and 4 in Table 3 report the predictions of the model for year 2000 and the actual data for that same year. The implicit education tax rate in year 2000 was 5.99 percent and the model predicts 5.83 percent. The model correctly predicts a higher number of native students enrolled in public schools in year 2000 than in 2008. According to our model the public school share for natives in 2000 should have been 7 percentage points higher than in 2008, which falls somewhat short of the 9.5 point difference in the data. The corresponding moments for the four immigrant groups are also well matched by the model. This also implies that the equilibrium values for year 2000 for the share of students in public schools for each group is close to that observed in the data. For instance, the model rightly predicts that African immigrants have the largest shares of public school use (86 percent, compared to 89 percent in the data) and natives have the lowest (60 percent, compared to 66 percent in the data). Finally, the model implies a ratio of public to private household income for year 2000 equal to 0.68 , somewhat lower than the value 0.75 in the data. The table also reports the public education spending per student and a measure of the quality of public education, namely, the number of education units received by students in public schools. ${ }^{41}$ Importantly, our calibrated model predicts accurately spending per student in public schools in year 2000 (2,276 euros compared to 2,337 euros in the data). Overall these figures provide validation of the use of our model for quantitative analysis and, specifically, regarding its ability to produce reasonable predictions regarding the school choices of each group and the quality of public education.

\footnotetext{
${ }^{40}$ We stress that we are keeping the values of parameters $\left(\alpha, \gamma_{0}, \gamma_{1}, \gamma_{2}, \gamma_{3}, \gamma_{4}, \sigma_{\lambda}\right)$ constant as reported in Table 2.

${ }^{41}$ For our main model, these two variables exactly coincide because the cost of educating immigrant children is taken to be the same as that of educating native children (and normalized to one).
} 


\section{Counterfactuals}

We are now ready to tackle the main goal of the paper. Namely, we want to evaluate what have been the effects of the 2000-2008 immigration wave on the school choices of the native population and on their political support for public education, together with the consequences for the funding and quality of public education.

We proceed in two stages. First, we quantify the effects resulting from the arrival of immigrants (and their children) between years 2000 and 2008. These effects operate through the changing views of native voters regarding the desired implicit tax rate and their public-private school choices. In this exercise immigrants affect tax revenue and the level of enrollment in public and private schools. For simplicity we refer to this exercise as the effect of immigration and we view it as materializing mainly in the short run.

The second stage adopts a more long-run perspective. Here we focus on the effects from naturalization of the immigrant population residing in Spain in year 2008. From our political-economy perspective the fundamental implication is the resulting change in the number and distribution of voters, which is likely to affect profoundly Spanish politics and, in particular, the political economy of public education. For short we refer to this exercise as the effect of naturalization. ${ }^{42}$ To the extent that average household income is lower for immigrant households than for native ones, naturalization will lead to a downward shift of the median voter along the income distribution.

\subsection{The Effects of Immigration}

In order to isolate the effects of the 2000-2008 immigration wave we conduct the following simulation exercise. Starting from our baseline scenario (income and demographics as in year 2008), we solve for the equilibrium in a scenario where the income distribution is as in $2008\left(g^{2008}\right)$ but where the size and composition of the immigrant population are as in year $2000\left(h^{2000}\right)$. The comparison between the two scenarios identifies the effects of immigration, holding income constant. The effects of immigration here will operate through the increase in the overall number of school-age children in the economy, taking into account the income and preferences toward education of their ethnic group.

Table 4 presents our findings. The first column reports the actual data for year 2008 for the implicit tax rate, public school enrollment for each of the 5 groups, and public

\footnotetext{
${ }^{42}$ This exercise can also be viewed as a robustness check on our first exercise given that even when immigrants are not franchised, it is possible that they influence the domestic politics of the host country. This can be the case if politicians/voters are foresighted and try to court the sympathies of the soon-to-be franchised immigrant population (Ortega (2005), Ortega (2010)).
} 
spending in education per student. Column 2 reports the same outcomes for the scenario where the foreign-born population in Spain equals, in size and origin composition, that of year 2000. As we discussed earlier, it is likely that the implicit tax rate will be lower in the counterfactual where the immigrant population is back to its year-2000 level. We now learn that the reduction in the tax rate is small (5.90 versus 5.93 percent in the benchmark and data). Let us now turn to the implications regarding the size of public education. In the counterfactual the total enrollment in public schools falls relative to the benchmark. In other words, immigration appears to have led to a sizable increase in the size of public education, namely, enrollment in public schools per 100 households has increased by 1.2 percentage points. Interestingly, this is the combination of two opposing effects: a large reduction in the number of native students in public schools (3.49 students per 100 households) and a large inflow of immigrant students into the system with a higher propensity than natives to attend public schools. Indeed the share of native children in public schools in the counterfactual is 0.76 percentage points higher (65.43 percent) than in the benchmark. Let us now turn to the effects of immigration on the quality of public education, measured by public spending per student. We find that in the counterfactual (with immigration as in year 2000) spending per student would have been 4,727 euros, which is 3.17 percent higher than in the benchmark.

It is interesting to compare our findings to those reported by Coen-Pirani (2011) in his analysis of the effects of immigration in California. ${ }^{43}$ He reports that, compared to the benchmark for that same year, if the immigrant population had remained as in 1970 (while allowing the income distribution to vary over time, as we do) the share of native children enrolled in public schools in 1980 would have been 0.17 percentage points higher, spending per student in public schools would have been 3 percent higher, and the total enrollment in public schools would have been 1.2 percentage points higher. ${ }^{44}$ These figures are very similar to our findings for Spain. ${ }^{45}$

Let us now examine a few alternative counterfactual scenarios. In column 3 we consider

\footnotetext{
${ }^{43}$ He studies an immigration episode that lasted 3 decades, between 1970 and 2000. The most relevant comparison to our analysis is when we focus on his findings for the 1970-1980 period. During that period the share of immigrant children enrolled in Californian schools increased by about 7.5 percentage points. This is only a bit smaller than 10 percentage-point increase in the immigrant share in schools (and in the working-age population) in Spain.

${ }^{44}$ Concerning his full period of analysis, Coen-Pirani (2011) reports that if immigration had remained at the 1970 level the share of native children enrolled in public schools in year 2000 in California would have been 1.12 percentage points higher and spending per student in public schools 24 percent higher than otherwise.

${ }^{45}$ The size of the immigration flow into the school system in California between 1970 and 1980, relative to the whole student body, was 25 percent smaller than the inflow in Spain between 2000 and 2008. Thus, at parity of inflows, the results for California in terms of the effects on the size and quality of public education would appear to be somewhat higher, but still comparable, to those found here.
} 
the scenario where the whole immigrant population is removed, as opposed to going back to the year-2000 immigrant population. Not surprisingly, the results are magnified. The tax rate is now slightly lower, at 5.88 percent and there is a larger native flight toward private schools. In the absence of all immigrants, the share of natives attending public schools would have been $65.71 \%$, or 1.04 percentage points higher. Additionally, the quality of public education would have been 4.38 percent higher (compared to 3.17 percent when going back to the immigrant population in year 2000). The remaining columns in Table 4 present sensitivity analysis along two different dimensions. In column 4 we report the results when we allow for a higher cost of educating immigrant children (10 percent). In this case the share of native children in public schools would have been a bit higher in the absence of immigration (66.08 versus 65.71 percent) and the quality of public education a slightly lower than in the previous column (no immigrants, same cost of education for natives and immigrants).

Column 5 presents the results of the opting-out version of our model used by CoenPirani (2011), where private schools are not subsidized (and the cost of education is the same for natives and immigrants). This exercise provides an important robustness check regarding how our results would have been affected if we had considered a smaller subsidy to private schools. The results here should be compared to column 2, the scenario where private schools are subsidized and the immigrant population is assumed to be as in year 2000. In the opting-out model, the counterfactual quality of public education would have been 3.76 percent higher than in the benchmark (compared to 3.17 percent in our main model). Regarding the size of public education in terms of overall enrollment, the optingout model delivers practically the same result as our main model. Finally, in terms of the native flight to private schools, the opting-out model implies a reduction in the share of native students in public schools due to immigration of 0.89 percentage points, compared to 0.76 points in our main model. As a result, we find differences in the magnitudes of the main effects between the opting-out model and our main model, although these differences are not large.

\subsection{The Effects of Naturalization}

We now focus on the effects of granting the right to vote to the immigrant population residing in Spain in year 2008. At this point the economy does not experience any changes in its demographic composition or in income. It is purely an exercise in franchise extension.

Table 5 reports the results. Again, column 1 reports the actual values of the moments for 
year 2008. Column 2 reports the values for the same moments in the counterfactual scenario where immigrants have been enfranchised using our main specification, that is, when private schools are subsidized and the cost of education is the same for native and immigrant children. We find a significantly lower implicit tax rate, at 5.50 percent, as opposed to 5.93 in the data. This leads to a large reduction in the quality of public education, with education units (spending) per student in public schools, falling by 7.68 percent. Naturally, we find a sizable reduction in the probability of using public schools for the native population, from 64.67 percent down to 62.54 percent. This roughly two percentage-point reduction is about twice as large as the short-run effect of immigration discussed above. Turning now to the effects on the size of public education (enrollment in public schools), our findings show that naturalization will be responsible for a small reduction in the size of public education. We estimate that the enrollment in public schools per 100 households will fall by 0.63 percentage points. In this case this is fully driven by native flight toward private schools caused by a sharp reduction in the quality of public education.

Columns 3 and 4 provide two robustness checks. In the specification in column 3 we assume that the cost of educating immigrants is 10 percent higher than the corresponding cost for natives. The implicit tax rate now is a bit higher, 5.55 versus 5.50 percent, but does not change the overall picture. Again the native flight to private schools is about 2 percentage points and the quality of public education falls by about 7 percent following naturalization. In column 4 we present the results for the opting-out scenario. The tax rate would now be 3.77 percent, ${ }^{46}$ and the reduction in the share of natives in public schools and in the quality of public education would be somewhat smaller than those in column 2 (respectively, 1 percentage point and 4.43 percent lower). While not dramatic, these differences suggest that the effects of naturalization do depend, to some extent, on the size of the subsidy to private schools.

In conclusion, our analysis predicts that the largest effects of immigration on the schooling system will arise because of the direct effect of immigration on domestic politics, once immigrants are naturalized and gain the right to vote.

\subsection{The combined effects of immigration and naturalization}

The previous decomposition of the effects of immigration into two stages once the immigrants arrive and their children are enrolled in school, and the consequences of their direct

\footnotetext{
${ }^{46}$ As discussed earlier, the tax rate is now much lower because taxes only need to finance public schools, and not the subsidy to private schools.
} 
political action once they are enfranchised, has been useful to flesh out the mechanisms at play. We now focus on the long-run effect of immigration, which combines the two effects discussed above (immigration and naturalization).

To do so we compare the difference in policies between the naturalization and the scenario where we assume that the immigrant population is as it was in year 2000. This exercise identifies the combined effect of immigration due to the arrival of immigrant households into the economy (and into the education system) as well as their direct effect on domestic politics once they are enfranchised. We focus on three outcomes: the size of public education (measured by the total enrollment in public schools), native flight (measured as the change in the native enrollment in public schools), and the quality of public education (measured by public spending per student).

The two counterfactual scenarios involved in the computation of the combined effects were already presented in detail in Table 4 and Table 5 . However, to simplify the exposition it is helpful to examine the summary reported in Table 6 . The top panel simply reproduces the relevant information from the previous two tables. The bottom panel reports the relevant changes that summarize the effects of immigration and naturalization, as defined earlier. In addition it reports the sum of the two partial effects, which we refer to as the combined effect.

Several features stand out. First, the combined effects of immigration and naturalization will lead to a small increase in the size of public education, with enrollment per 100 households increasing by 0.63 . However, this increase in size masks an important composition effect. On the one hand there is a large reduction in the enrollment of native students in public schools (who flee toward private schools). This reduction is nevertheless offset by a large inflow of immigrant students into public schools (equal to 4.12 students per 100 households). Secondly, there will be a large reduction in the quality of public education. We estimate that public spending per student will fall by almost 11 percent. Our analysis suggests that these effects will unfold unevenly over time. While the changes in the size (and student composition) of public schools will take place promptly, upon arrival of the immigrants, the reduction in funding will be more gradual and only fully take place once the immigrant population has been fully enfranchised.

Finally, it is interesting to examine how our conclusions would have changed if we had ignored the existence of the subsidy. To do so we repeat the analysis but now we use the opting-out model. The general pattern is similar, but the quantitative predictions differ somewhat. The combined effect of immigration and naturalization on the size of public 
education would have been larger, with an increase of 0.81 students per 100 households as opposed to 0.63 in the model with the subsidy. Again this is the result of an important native flight toward private schools and an even larger inflow of immigrant children into public schools, which is now slightly smaller than in the model with subsidy. This is the reflection of the smaller reduction in the quality of public education (public spending per student), which is now 8 percent of the benchmark value, compared to almost 11 percent when we take into account the role of the subsidy. In conclusion, while accounting for the subsidy does not change the qualitative picture, it does change significantly the quantitative predictions.

\section{Regional education policies}

Regional governments in Spain have a great degree of autonomy in decisions regarding education. ${ }^{47}$ As a result, the available proxy measures for quality of public education exhibit substantial regional variation. ${ }^{48}$ In addition to the variation in education policies, the size of the immigration flows, relative to population, has differed greatly across regions in our period of study. The foreign-born share in year 2008 ranges from 22.87 percent (Balearic islands) to 3.91 percent (Extremadura), compared to a national average of 13.10 percent. In addition the ethnic composition of the immigrant population across regions also varies widely.

It is thus interesting to analyze the effects of immigration and naturalization under the assumption that education policies are decided at the regional level, and taking into account the regional heterogeneity in the size and ethnic composition of immigration flows. In particular, we are interested in three questions. First, we want to examine the implications of our analysis for the effects of immigration and naturalization on the size (overall enrollment) and quality (spending per student) of public education for each Spanish region. Second, we want to evaluate the size of the native flight toward private schools in each region, and compare that to existing empirical (reduced-form) estimates of that effect. Finally, we ask

\footnotetext{
${ }^{47}$ Seven regions (autonomous communities) in Spain have a large degree of autonomy regarding education, while the others have chosen to follow the policy dictated by the central government. Ciccone and Garcia-Fontes (2009) provide a comparison of the quality of public education for Spanish regions from an international perspective.

${ }^{48}$ In 2010 the average Spanish region had 7.94 students per teacher in public schools. However, this variable ranged from 6.29 to 9.58 . Another commonly used measure of quality is the dropout rate, which also varies widely across Spanish regions. For instance in 2010 the share of the population age 18-24 that had not completed the non-compulsory stage of secondary education was 28.4 percent at the national level. However, this drop-out rate ranged from 12.6 percent (Basque Country) to over 35 percent (Murcia or Balearic Islands).
} 
whether the wave of immigration has increased or decreased regional inequalities in terms of education policies.

We begin with a description of regional differences. The top panel in Table 7 presents some summary statistics for year 2008. As noted earlier, there is a great deal of variation in the size of the immigrant population across Spanish regions. This is also the case for the implicit tax rate, which ranges between 3.52 and 8.54 percent of household income, and for public education spending per student, which ranges between 3,512 and 5,893 euros. Perhaps the most striking dimension of regional heterogeneity in education in Spain are the large differences in the reliance on public schools. In year 2008 the share of the native population using public schools ranged from 46 percent (Basque country) to 80 percent (Castilla la Mancha), with a national average of 65 percent. ${ }^{49}$

Next we take the parameter values obtained from the calibration of our model to Spain as a whole (Table 2) and impose them on all regions. We then feed the model with each region's income distribution and demographic data and compute the equilibrium under each scenario region by region. ${ }^{50}$ The second panel in the table reports the values for year 2008 , where each region has been assigned its 2008 data. As we know, our calibration ensures that the implicit tax rate, public education spending per student, and the share of natives in public school (as well as for each immigrant group) are perfectly matched in year 2008 for Spain as a whole. Naturally, this is not the case region by region.

Comparing data and fitted values, we note that the averages for the three variables are similar. However, the model generates less variation for the implicit tax rate and the share of natives in public schools than is observed in the data. The coefficients of variation are $1 / 3$ to $1 / 4$ of those for the data. In contrast there is smaller variation in public spending per student in the data. ${ }^{51}$ At any rate there is substantial correlation between the educational policies in the data and in the fitted regional model, at 0.41 for the implicit tax rate and 0.48 for public spending per student.

\footnotetext{
${ }^{49}$ Accounting for the large degree of cross-regional disparities is an interesting question but beyond the scope of our paper. Regional differences along several dimensions are likely to play a role: political ideology, income, culture and history. Here we simply take these disparities as given and attempt to isolate the effects of immigration region by region.

${ }^{50}$ So far we have assumed that educational preferences are homogeneous across regions within Spain. It is feasible, and potentially interesting, to allow for regional differences in preferences, perhaps linked to different labor market returns of education.

${ }^{51}$ This is quite intuitive. Our regional model ignores the fact that in reality the central government plays an important redistributive role. As a result, the actual public education spending per student shows lower regional variation than the predicted one.
} 


\subsection{The combined effect on education policy}

We now turn to the effects of immigration on the size and quality of public education. We report both the effects of immigration and those of naturalization separately, as we did for Spain as a whole. However, our focus will be on the combined effect, which can be gauged easily by examining the difference between the educational policies in the naturalization scenario and those in the scenario where the immigrant population is as in year 2000 . This exercise identifies the combined effect of immigration due to the arrival of immigrant households into the economy (and into the education system) as well as their direct effect on domestic politics once they are enfranchised.

The bottom panel in the Table presents the combined effect on the main outcomes of interest. Let us first comment on the range of effects on the size of public education across Spanish regions. As we know from our earlier analysis, the combined effect of immigration and naturalization for Spain as a whole will be a small increase in enrollment in public schools, 0.63 students per 100 households. However, there is a great deal of regional heterogeneity, ranging from a reduction of 0.70 students per 100 households to an increase in 2.17 students per 100 households. Based on our calculations, both Catalonia and Madrid are expected to experience significant increases (1.17 and 0.85 students per 100 households, respectively). The increase in overall enrollment in public schools in these regions (as well and in all others) masks a large native flight to private schools, which we discuss in more detail in the next section. We now turn to the effects on the quality of public education, measured by public spending per student. As discussed earlier, the combined effect for Spain as a whole is a 10.85 percent reduction in this variable. Across regions, the reductions in the quality of public education range from 2.79 to 24.84 percent. In Catalonia and Madrid the forecasted reductions are 16.56 and 12.17 percent, respectively.

It is also interesting to correlate the changes in public spending per student due to immigration and naturalization with the foreign-born share in year 2008. The latter summarizes well the size of the immigration flow experienced by each region, relative to its population. ${ }^{52}$ Figure 2 plots these data. The Figure reveals a clear and statistically significant negative association. The estimated slope coefficient implies that a 10 percentage-point difference in the foreign-born share (in year 2008) between two regions accounts for a difference of 431 euros in spending per student (9.6 percent of the average value in the data). This elasticity is a useful object since it can be applied to produce back-of-the-envelope predictions for

\footnotetext{
${ }^{52}$ The results are very similar if we replace the 2008 foreign-born share by the 2000-2008 change in the foreign-born share in each region.
} 
other immigration episodes. Roughly speaking, it suggests that if a region experiences an immigration flow amounting to 5 percent of its population we should expect public spending per student to fall by slightly less than 5 percent, once immigrants become naturalized and the combined effect takes place.

\subsection{Immigration and Native Flight to Private Schools}

A large body of empirical literature for the US and other countries has documented that immigration seems to lead to a native flight away from public schools and toward private ones, as well as changes in residence toward areas with better public schools. Most of those studies are eminently empirical and estimate reduced-form models (e.g. Betts and Fairlie (2003), Cascio and Lewis (2012), or Farre et al. (2014)).

Our analysis here can provide a structural interpretation for those estimates. It is also interesting to compare the magnitude implied by our model to those obtained from the reduced-form estimates. As in the previous section we report the change in the share of native students enrolled in public schools between the naturalization scenario and the scenario where we assume that each region's immigrant population is as in year 2000, that is, the combined effect. Figure 3 presents the results. The relationship is negative and highly significant, confirming that regions that received larger immigrant inflows (relative to their population) suffered larger declines in the share of public school use among native households. The estimated slope coefficient implies that a 10 percentage-point increase in the regional foreign-born share leads to a 2.7 percentage-point reduction in the share of native students enrolled in public schools.

In their reduced-form, empirical analysis of Spain's immigration wave Farre et al. (2014) report that immigration might have been responsible for a 10 percentage-point reduction in in the share of households using public schools. ${ }^{53}$ In comparison, the size of the native flight predicted by our model is just a fraction of the effect uncovered by the reduced-form estimates. This is intuitive since in our theoretical model there is a single mechanism powering the native flight to private schools, namely, changes in the quality of public schools driven by political economy considerations. In reality, there may also be other mechanisms that can reinforce the process, such as peer effects within the school, congestion in other public services (e.g. healthcare), or xenophobia. The reduced-form estimate can be interpreted as reporting the overall effect of the native flight although, of course, it is not able to apportion

\footnotetext{
${ }^{53}$ Note that here we refer to the share of students enrolled in public schools, not to the share of households. However, changes in both measures are likely to be similar.
} 
the effect across the multiple mechanisms. Our analysis suggests that the political economy channel affecting the quality of public schools may be responsible for approximately one quarter of the total effect, leaving a wide margin to the other mechanisms.

\subsection{Regional inequality in education policy}

It is also interesting to examine whether immigration has increased or decreased regional inequalities in public education policy. We consider the two dimensions of education policy in our model: the implicit tax rate and public education spending per student.

Let us begin by examining whether immigration has induced convergence in the implicit tax rates. Figure 4 correlates the tax rate in the counterfactual with year- 2000 immigration levels and the difference in the tax rate between the naturalization and the no-migration scenarios, our measure of the combined effect of immigration on education policies. ${ }^{54} \mathrm{We}$ also plot the linear fit resulting from a least-squares estimation. There is a clear and statistically significant negative association between the two variables. The degree of convergence is also economically large, with an estimated slope coefficient of -0.50 .

Our interpretation for the finding that immigration has led to convergence in implicit tax rates is as follows. Immigrants are likely to flock disproportionately to regions with high implicit tax rates. One reason why a region may have a high tax rate in our model is high median income relative to mean income. ${ }^{55}$ This may be used by immigrants as a criterion to choose the region where they expect to earn higher income. The positive association between immigration, relative to population, and implicit tax rates is indeed confirmed by the data. ${ }^{56}$ To the extent that immigrants have lower income than natives on average, when they naturalize the median voter will shift downward in the income distribution and impose a lower tax rate. Hence, the regions with high initial tax rates attract more immigrants and, once these immigrants naturalize, these regions will experience larger reductions in their tax rate.

Let us now turn to public education expenditure per student. Figure 5 reports the corresponding convergence regression. While we also find a negative association between the initial level and the change in the variable, the slope is very small (-0.08) and in fact we

\footnotetext{
${ }^{54}$ As seen in the Figure, region 3 (Asturias) had the lowest tax rate in the year-2000-immigration scenario and region 15 (Navarra) had the highest.

${ }^{55}$ Note that the preferred tax rate in Equation (8) is increasing in $y^{\text {med }} / \bar{y}$, provided $\alpha<0$, where $y^{\text {med }}$ is the income of the median voter.

${ }^{56}$ The three regions with the lowest tax rates in the counterfactual with low (year 2000) immigration were Asturias (3), the Basque country (16) and Galicia (12), also characterized by the lowest immigration flows. Their foreign-born shares in 2008 were, respectively, $5.84 \%, 6.60 \%$, and $7.04 \%$, while for Spain as a whole it was $13.10 \%$.
} 
cannot reject a zero coefficient. In words, we observe a much smaller degree of convergence in the quality of public education. What accounts for this differential pattern in the two dimensions of our education policies? The data shows that there is virtually zero correlation between the size of the immigration flows in a region and its initial public spending per student. ${ }^{57}$ Thus we do not observe any measurable convergence in public spending per student. Interestingly, this finding is similar to that reported by Armenter and Ortega (2010) in a model with endogenous migration and income redistribution calibrated to U.S. states. These authors report that inter-state migration has induced substantial convergence in tax rates across U.S. states. They also find a much smaller degree of convergence in state-level redistributive transfers due to an offsetting tax-base effect.

\section{Conclusions}

Our goal in this paper has been to analyze the effects of immigration on the education system of the receiving country, focusing on the repercussions for the political economy of public education. We have tailored our model to Spain's education system, which is characterized by a large subsidy to private schools and, not surprisingly, a large share of the student body enrolled in private schools.

Our main finding has been that the long-run effects of immigration, which will take place after the immigrant population has been naturalized, will lead to a small increase in the size of public education, measured by enrollment in public schools. However, this increase in size masks an important fact: a large reduction in the enrollment of native students in public schools (who flee toward private schools). In addition, we find that as a result of immigration there will be a large reduction in the quality of public education, measured by public spending per student. Our analysis suggests that these effects will unfold unevenly over time. While the changes in the size (and student composition) of public schools will take place promptly, upon arrival of the immigrants, the reduction in funding will be more gradual and only fully take place once the immigrant population has been fully enfranchised. Thus we predict that the ongoing native flight toward private schools will be intensified over the next decade. It is also possible that some of these effects materialize faster, since immigrants may influence politicians and policies through means other than voting. Perhaps foresighted politicians may have already started courting the

\footnotetext{
${ }^{57}$ This is so because regions with initially high tax rates had low spending per student. Among the regions with the lowest initial spending per student, some had above-average immigration flows while others had below-average inflows of immigrants (relative to population).
} 
sympathy of the soon-to-be voters.

Naturally, the exact quantitative implications of our analysis rely on the validity of the assumptions we have made. While we have experimented along several dimensions, one caveat is particularly relevant. For simplicity we have assumed that taxes are linear. Clearly, this is not realistic since most countries have progressive tax systems. If we were to assume, also unrealistically, that governments can perfectly redistribute income from rich to poor individuals our findings would be deeply affected. However, in our view introducing realistic levels of progressivity in the analysis would affect the quantitative predictions, but not the qualitative findings.

These findings have important consequences for income inequality. They strongly suggest that public schools will experience important pressures to teach larger numbers of students with smaller budgets. Naturally, the quality of public education is likely to deteriorate, along with the chances of immigrant children to attend college and to succeed in the labor market. As a result, the social and economic assimilation of these children will be seriously threatened. Besides undermining their own chances of upward economic mobility, social cohesion may also be negatively affected. 


\section{References}

Albornoz-Crespo, Facundo, Antonio Cabrales, and Esther Hauk, "Immigration and the School System," CEPR Discussion Papers 8653, C.E.P.R. Discussion Papers November 2011.

Anghel, Brindusa and Antonio Cabrales, "The Determinants of Success in Primary Education in Spain," Working Papers 2010-20, FEDEA July 2010.

Arellano, Manuel and Gema Zamarro, "The choice between public and private schools with or without subsidies in Spain," Technical Report, CEMFI 2007.

Armenter, Roc and Francesc Ortega, "Credible Redistributive Policies and Migration across US States," Review of Economic Dynamics, April 2010, 13 (2), 403-423.

Bergstrom, Theodore C, Daniel L Rubinfeld, and Perry Shapiro, "Micro-Based Estimates of Demand Functions for Local School Expenditures," Econometrica, September 1982, 50 (5), 1183-1205.

Betts, Julian R. and Robert W. Fairlie, "Does immigration induce 'native flight' from public schools into private schools?," Journal of Public Economics, May 2003, 87 (5-6), 9871012 .

Blankenau, William F., Nicole B. Simpson, and Marc Tomljanovich, "Public Education Expenditures, Taxation, and Growth: Linking Data to Theory," American Economic Review, May 2007, 97 (2), 393-397.

Calero, Jorge and Josep-Oriol Escardibul, "Evaluacion de servicios educativos: el rendimiento en los centros publicos y privados medido en PISA-2003," Hacienda Publica Espanola, 2007, 4, 33-66.

Cascio, Elizabeth U. and Ethan G. Lewis, "Cracks in the Melting Pot: Immigration, School Choice, and Segregation," American Economic Journal: Economic Policy, August 2012, $4(3), 91-117$.

Ciccone, Antonio and Walter Garcia-Fontes, "The quality of the Catalan and Spanish education systems: A perspective from PISA," IESE Research Papers D/810, IESE Business School July 2009.

Coen-Pirani, Daniele, "Immigration and Spending on Public Education: California, 19702000," Journal of Public Economics, 2011, 95 (11).

de la Rica, Sara and Francesc Ortega, "Economic and Cultural Gaps among Foreign-born Minorities in Spain," "Edited by Yann Algan, Alberto Bisin, Alan Manning, and Thierry Verdier" ISBN 978-0-19- 966009-4, "In Studies of Policy Reform, Oxford Economic Press" 2012.

del Pozo, D. Trillo, M. Perez Garrido, and J.M. Crespo, "Analisis economico del rendimiento en la prueba de conocimientos y destrezas imprescindibles de la comunidad de Madrid," Technical Report 13, Instituto de Estudios Fiscales 2006.

Dottori, Davide, Fernanda Estevan, and I-Ling Shen, "Reshaping the schooling system: The role of immigration," Journal of Economic Theory, 2013, 148 (5), 2124-2149.

Epple, Dennis and Richard E. Romano, "Ends against the middle: Determining public service provision when there are private alternatives," Journal of Public Economics, November 1996, 62 (3), 297-325. 
- and Richard E Romano, "Public Provision of Private Goods," Journal of Political Economy, February 1996, 104 (1), 57-84.

Farre, Lidia, Francesc Ortega, and Ryuichi Tanaka, "Immigration and School Choices in the midst of the Great Recession," Mimeo 2014.

Fernandez, Raquel and Richard Rogerson, "On the Political Economy of Education Subsidies," Review of Economic Studies, April 1995, 62 (2), 249-62.

- and _. "Income Distribution, Communities, and the Quality of Public Education," The Quarterly Journal of Economics, February 1996, 111 (1), 135-64.

_ and _ , "Public Education and Income Distribution: A Dynamic Quantitative Evaluation of Education-Finance Reform," American Economic Review, September 1998, 88 (4), 813-33.

_ and _, "Education finance reform and investment in human capital: lessons from California," Journal of Public Economics, December 1999, 74 (3), 327-350.

Galor, Oded and Joseph Zeira, "Income Distribution and Macroeconomics," Review of Economic Studies, January 1993, 60 (1), 35-52.

Glomm, Gerhard and B Ravikumar, "Public versus Private Investment in Human Capital Endogenous Growth and Income Inequality," Journal of Political Economy, August 1992, $100(4), 818-34$.

Goyette, Kimberly and Yu Xie, "Educational Expectations of Asian American Youths: Determinants and Ethnic Differences," Sociology of Education, 1999, 72 (1), pp. 22-36.

Gradstein, Mark and Moshe Justman, "Education, Social Cohesion, and Economic Growth," American Economic Review, September 2002, 92 (4), 1192-1204.

Hsin, Amy and Yu Xie, "Explaining Asian American's Academic Advantage Over Whites," Proceedings of the National Academy of Sciences, 2014, p. Forthcoming.

OCU, "The growing school expenses (in Spanish)," Technical Report 373, Organizacion de Consumidores y Usuarios September 2012.

Ortega, Francesc, "Immigration quotas and skill upgrading," Journal of Public Economics, September 2005, 89 (9-10), 1841-1863.

_ , "Immigration, Citizenship, and the Size of Government," The B.E. Journal of Economic Analysis 85 Policy, March 2010, 10 (1), 1-40.

Razin, Assaf, Efraim Sadka, and Phillip Swagel, "Tax burden and migration: a political economy theory and evidence," Journal of Public Economics, August 2002, 85 (2), 167190.

Speciale, Biagio, "Does immigration affect public education expenditures? Quasiexperimental evidence," Journal of Public Economics, 2012, 96 (910), 773 - 783.

Takii, Katsuya and Ryuichi Tanaka, "Does the diversity of human capital increase GDP? A comparison of education systems," Journal of Public Economics, August 2009, 93 (7-8), 998-1007.

Vernby, Kre, "Inclusion and Public Policy: Evidence from Swedens Introduction of Noncitizen Suffrage," American Journal of Political Science, 2013, 57 (1), 15-29. 
Table 1: Descriptive statistics

\begin{tabular}{|c|c|c|c|}
\hline Variable & 2000 & 2008 & Change \\
\hline GDP & 100 & 173 & $73 \%$ \\
\hline Real GDP & 100 & 132 & $32 \%$ \\
\hline Population (working-age) & $27,324,284$ & $31,410,915$ & $14.95 \%$ \\
\hline Foreign-born share $(\%)$ & 3.64 & 13.10 & 9.46 \\
\hline Number of households $^{1}$ & $9,469,548$ & $12,762,903$ & $34.78 \%$ \\
\hline \multicolumn{4}{|l|}{ Share (100) } \\
\hline Native households & 97.03 & 86.19 & -10.84 \\
\hline Immigrant households ${ }^{2}$ & 2.97 & 13.81 & 10.84 \\
\hline Europe & 1.38 & 5.09 & 3.71 \\
\hline Africa & 0.79 & 2.62 & 1.84 \\
\hline America & 0.61 & 5.62 & 5.01 \\
\hline Asia and Oceania & 0.19 & 0.48 & 0.29 \\
\hline Average household income ${ }^{3}$ & 17,717 euros & 29,229 euros & $64.98 \%$ \\
\hline Native households & . & 29,403 euros & . \\
\hline Immigrant households & . & 26,250 euros & . \\
\hline Share of students in public schools & 0.662 & 0.697 & 0.035 \\
\hline Natives & 0.66 & 0.65 & -0.01 \\
\hline Immigrants & 0.77 & 0.83 & 0.06 \\
\hline Europe & 0.69 & 0.82 & 0.13 \\
\hline Africa & 0.89 & 0.90 & 0.01 \\
\hline America & 0.77 & 0.80 & 0.03 \\
\hline Asia and Oceania & 0.67 & 0.75 & 0.08 \\
\hline Overall public spending in education / GDP $4(\%)$ & 2.70 & 2.93 & 0.23 \\
\hline Public schools / GDP & 2.24 & 2.39 & 0.15 \\
\hline Subsidy to private / GDP & 0.46 & 0.54 & 0.09 \\
\hline
\end{tabular}

Notes: (1) Estimated on the basis of the Labor Force Survey. (2) Europe includes all countries in the European continent except for Spain. America includes North, Central and South America. (3) Average household income computed using the Family Expenditure Survey for year 2008 at current prices (nominal income). It includes salary, capital income and benefits. We multiplied the monthly income by 14 (12 months and double pay in August and December). (4) Overall public spending in education here covers pre-university education (preschool, elementary, secondary and special education) and includes the subsidies to private schools. 
Table 2: Calibration parameters

\begin{tabular}{lccc}
\hline \hline & $(1)$ & $(2)$ & $(3)$ \\
Specification & Main & Higher cost immig. & $\begin{array}{c}\text { Opting-out } \\
\text { Relative cost of education immig. }\end{array}$ \\
\hline$\alpha$ & -0.87 & -0.84 & -0.709 \\
& & & \\
$\mu_{\lambda}$ & 3.33 & 3.22 & 1.353 \\
$\sigma_{\lambda}$ & 2.58 & 2.54 & 1.645 \\
& & & \\
$\gamma_{0}$ (Native) & 0.52 & 0.48 & 0.015 \\
$\gamma_{1}$ (Imm. Europe) & 0.16 & 0.17 & 0.005 \\
$\gamma_{2}$ (Imm. Africa) & 0.12 & 0.13 & 0.004 \\
$\gamma_{3}$ (Imm. America) & 0.21 & 0.22 & 0.006 \\
$\gamma_{4}$ (Imm. Asia and Oceania) & 0.39 & 0.40 & 0.011 \\
& & & \\
$p_{0}$ & 1 & 1 & 1 \\
$p_{1}$ & 1 & 1.10 & 1 \\
$p_{2}$ & 1 & 1.10 & 1 \\
$p_{3}$ & 1 & 1.10 & 1 \\
$p_{4}$ & 1 & 1.10 & \\
\hline \hline
\end{tabular}

Notes: Specification (1) assumes identical cost of education for all 5 groups, and subsidy equal to spending per student in public schools. Specification (2) assumes that the cost of education for immigrants is 10 percent higher than for natives. Specification (3) refers to the opting-out model. Here there is no subsidy for private schools. The implied price-elasticities (in absolute terms) are $0.53,0.54$, and 0.58 , respectively. 
Table 3: Model predictions - Validation

\begin{tabular}{|c|c|c|c|c|}
\hline & $(1)$ & $\overline{(2)}$ & $(3)$ & $(4)$ \\
\hline \multirow[t]{2}{*}{ Year } & 2008 & 2008 & 2000 & 2000 \\
\hline & Data & Model & Data & Model \\
\hline${\text { Implicit tax } \text { rate }^{1}(\%)}$ & 5.93 & 5.93 & 5.99 & 5.83 \\
\hline Public school students per 100 households & 24.88 & 24.88 & 30.29 & 27.83 \\
\hline Natives & 19.67 & 19.67 & 29.06 & 26.59 \\
\hline \multicolumn{5}{|l|}{ Immigrants } \\
\hline Europe & 1.55 & 1.55 & 0.28 & 0.31 \\
\hline Africa & 1.16 & 1.16 & 0.54 & 0.52 \\
\hline America & 2.31 & 2.31 & 0.27 & 0.26 \\
\hline Asia and Oceania & 0.18 & 0.18 & 0.13 & 0.14 \\
\hline Ratio public-private household income & 0.73 & 0.73 & 0.75 & 0.68 \\
\hline \multicolumn{5}{|l|}{ Share of the students in group in public schools (\%) } \\
\hline Natives & 64.67 & 64.67 & 65.97 & 60.36 \\
\hline \multicolumn{5}{|l|}{ Immigrants } \\
\hline Europe & 81.89 & 81.89 & 69.13 & 76.76 \\
\hline Africa & 89.53 & 89.53 & 89.21 & 86.28 \\
\hline America & 79.78 & 79.78 & 77.27 & 74.44 \\
\hline Asia and Oceania & 75.39 & 75.39 & 67.04 & 72.50 \\
\hline Public education spending per student ${ }^{2}$ (euros) & 4,582 & 4,582 & 2,337 & 2,276 \\
\hline Quality of public education ${ }^{3}$ & 4,582 & 4,582 & 2,337 & 2,276 \\
\hline
\end{tabular}

Notes: (1) The implicit tax rate is equal to the overall public spending on education over aggregate household income; (2) Total public expenditure in education (including subsidy to private schools) divided by the enrollment in public and subsidized (concerted) private. Both the numerator and denominator refer to all pre-university education levels. In our model it coincides with the education services per student in public schools. (3) We define the quality of public education as the number of education units per student received in public schools. The cost of one education unit equals one for natives and $p_{m}$ for immigrants of group $m$. In this table $p_{m}=1$ for all groups. 
Table 4: Counterfactual Experiments: the Effects of Immigration

\begin{tabular}{|c|c|c|c|c|c|}
\hline & 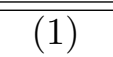 & 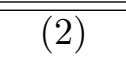 & 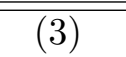 & 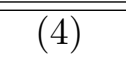 & 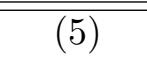 \\
\hline Specification & Data & Main & Main & Main & Opt-out \\
\hline Immigrant population & 2008 & 2000 & None & None & 2000 \\
\hline Relative cost immigrants & . & 1 & 1 & 1.10 & 1 \\
\hline Implicit tax rate $^{1}(\%)$ & 5.93 & 5.90 & 5.88 & 5.87 & 3.93 \\
\hline Public school students per 100 households & 24.88 & 23.62 & 23.19 & 23.32 & 23.66 \\
\hline Natives & 19.67 & 22.52 & 23.19 & 23.32 & 22.56 \\
\hline \multicolumn{6}{|l|}{ Immigrants } \\
\hline Europe & 1.55 & 0.28 & 0 & 0 & 0.28 \\
\hline Africa & 1.16 & 0.46 & 0 & 0 & 0.46 \\
\hline America & 2.31 & 0.24 & 0 & 0 & 0.24 \\
\hline Asia and Oceania & 0.18 & 0.13 & 0 & 0 & 0.13 \\
\hline \multicolumn{6}{|l|}{ Share of the students in public schools (\%) } \\
\hline Natives & 64.67 & 65.43 & 65.71 & 66.08 & 65.56 \\
\hline \multicolumn{6}{|l|}{ Immigrants } \\
\hline Europe & 81.89 & 81.84 & 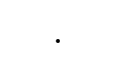 & . & 81.88 \\
\hline Africa & 89.53 & 89.83 & . & . & 89.91 \\
\hline America & 79.78 & 79.95 & . & . & 80.03 \\
\hline Asia and Oceania & 75.39 & 78.57 & . & . & 78.93 \\
\hline Public education spending per student ${ }^{2}$ (euros) & 4,582 & 4,727 & 4,783 & 4,774 & 4,755 \\
\hline Quality of public education ${ }^{3}$ & 4,582 & 4,727 & 4,783 & 4,774 & 4,755 \\
\hline Pct. chg. quality of public education ${ }^{4}$ & & $3.17 \%$ & $4.38 \%$ & $4.18 \%$ & $3.76 \%$ \\
\hline
\end{tabular}

Notes: Income distribution is fixed at 2008 level across all specifications. In column 1, the immigrant population is as in the data for year 2008. In columns 2 and 5, the immigrant population is as in the data in year 2000. In columns 3 and 4 we assume that there are no immigrants. (1) The implicit tax rate is equal to the overall public spending on education over aggregate household income; (2) Total public expenditure in education (including subsidy to private schools) divided by the enrollment in public and subsidized (concerted) private. Both the numerator and denominator refer to all pre-university education levels. In our model it coincides with the education services per student in public schools. (3) We define the quality of public education as the number of education units per student received in public schools. The cost of one education unit equals one for natives and $p_{m}$ for immigrants of group $m$. (4) This is the change in the average education services per student between the value in the corresponding column and the value in the first column (actual in 2008) as a percent of the value in the first column. 
Table 5: Counterfactual Experiments: the Effects of Naturalization

\begin{tabular}{|c|c|c|c|c|}
\hline & (1) & $(2)$ & $(3)$ & $(4)$ \\
\hline Specification & Data & Main & Main & Opt-out \\
\hline Immigrant population & 2008 & 2008 & 2008 & 2008 \\
\hline Relative cost immigrants & . & 1 & 1.10 & 1 \\
\hline Implicit tax rate ${ }^{1}(\%)$ & 5.93 & 5.50 & 5.55 & 3.77 \\
\hline Public school students per 100 households & 24.88 & 24.25 & 24.33 & 24.47 \\
\hline Natives & 19.67 & 19.03 & 19.10 & 19.31 \\
\hline \multicolumn{5}{|l|}{ Immigrants } \\
\hline Europe & 1.55 & 1.56 & 1.56 & 1.54 \\
\hline Africa & 1.16 & 1.15 & 1.15 & 1.15 \\
\hline America & 2.31 & 2.33 & 2.33 & 2.29 \\
\hline Asia and Oceania & 0.18 & 0.18 & 0.18 & 0.18 \\
\hline \multicolumn{5}{|l|}{ Share of the students in public schools (\%) } \\
\hline Natives & 64.67 & 62.54 & 62.77 & 63.47 \\
\hline \multicolumn{5}{|l|}{ Immigrants } \\
\hline Europe & 81.89 & 82.29 & 82.45 & 81.07 \\
\hline Africa & 89.53 & 88.87 & 88.99 & 88.93 \\
\hline America & 79.78 & 80.29 & 80.47 & 78.86 \\
\hline Asia and Oceania & 75.39 & 74.92 & 75.12 & 74.39 \\
\hline Avg. education spending per student ${ }^{2}$ & 4,582 & 4,230 & 4,195 & 4,380 \\
\hline Quality of public education ${ }^{3}$ & 4,582 & 4,230 & 4,268 & 4,380 \\
\hline Pct. chg. quality of public education ${ }^{4}$ & 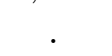 & $-7.68 \%$ & $-6.86 \%$ & $-4.43 \%$ \\
\hline
\end{tabular}

Notes: The immigrant population and the income distribution are kept fixed at their 2008 level. The counterfactual in columns 2-4 assumes that all immigrants gain the right to vote. (1) The implicit tax rate is equal to the overall public spending on education over aggregate household income; (2) Total public expenditure in education (including subsidy to private schools) divided by the total enrollment (public and subsidized private). Both the numerator and denominator refer to all pre-university education levels. (3) Analogous to (2) but now in terms of the education units received by each student. (4) This is the change in the average education services per student between the value in the corresponding column and the value in the first column (actual in 2008) as a percent of the value in the first column. 


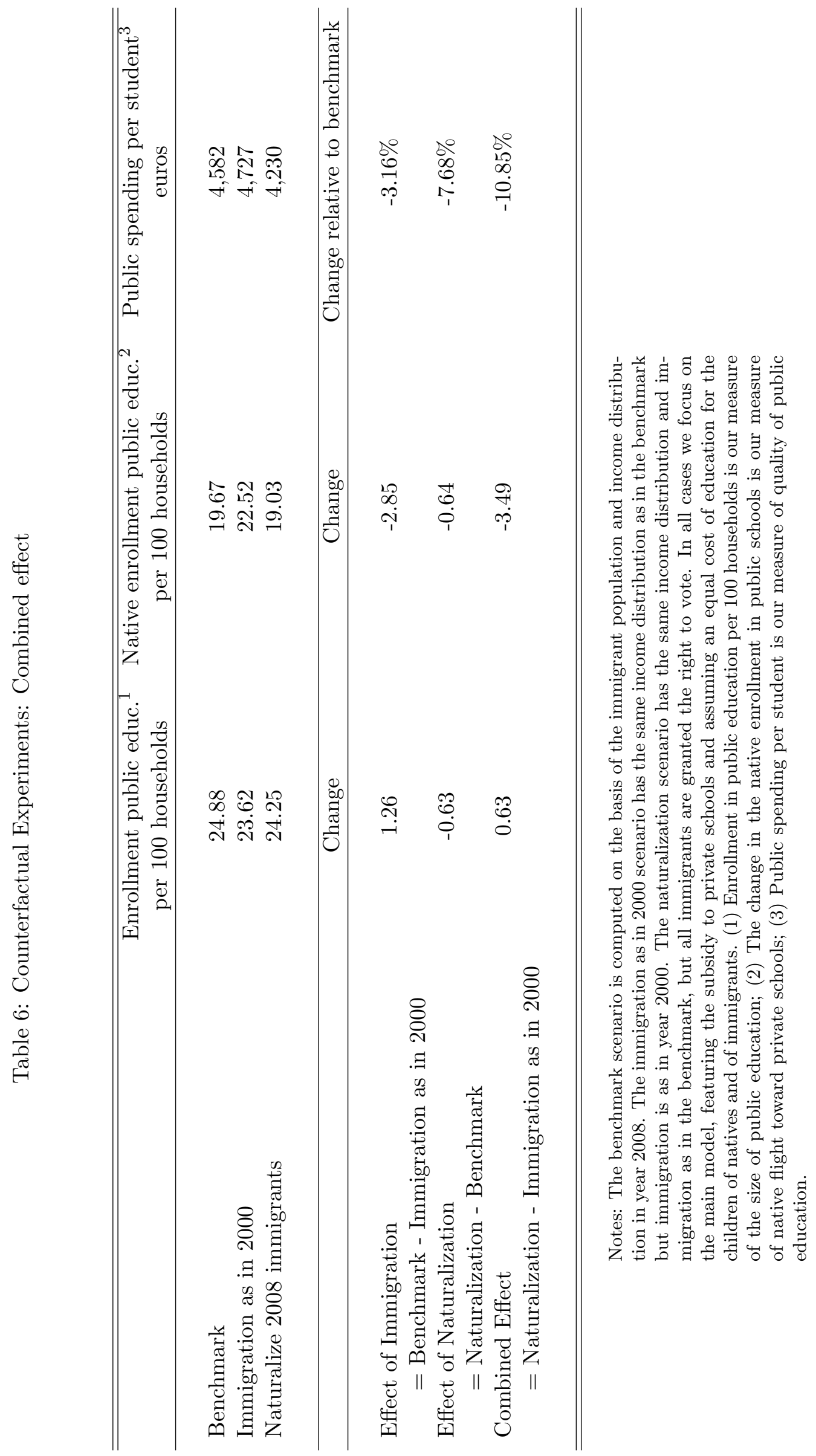


Table 7: Regional Education Policies

\begin{tabular}{|c|c|c|c|c|c|c|c|}
\hline & $\begin{array}{c}(1) \\
\text { Spain } \\
\end{array}$ & $\begin{array}{c}(2) \\
\text { Avg } \\
\end{array}$ & $\begin{array}{c}(3) \\
\text { Min } \\
\end{array}$ & $\begin{array}{c}(4) \\
\operatorname{Max}\end{array}$ & $\begin{array}{l}(5) \\
\text { CV } \\
\end{array}$ & $\begin{array}{c}(6) \\
\text { CAT }\end{array}$ & $\begin{array}{c}(7) \\
\text { MAD }\end{array}$ \\
\hline \multicolumn{8}{|l|}{ Data 2008} \\
\hline FBSH & 13.10 & 12.13 & 3.91 & 22.87 & 0.45 & 16.36 & 18.47 \\
\hline Public enrollment per 100 households & 24.88 & 31.63 & 13.90 & 34.65 & 0.25 & 23.98 & 18.63 \\
\hline Native public enrollment per 100 households & 19.67 & 28.17 & 12.65 & 31.71 & 0.28 & 15.68 & 13.10 \\
\hline Share natives in public schools & 64.67 & 64.56 & 46.31 & 80.46 & 0.14 & 58.27 & 48.13 \\
\hline Implicit tax rate $(\%)$ & 5.93 & 5.81 & 3.52 & 8.64 & 0.20 & 5.34 & 3.52 \\
\hline Public educ. spending per student (euros) & 4,582 & 4,467 & 3,512 & 5,893 & 0.13 & 4,076 & 3,531 \\
\hline \multicolumn{8}{|l|}{ Benchmark (fitted values 2008) } \\
\hline Public enrollment per 100 households & 24.88 & 24.37 & 17.68 & 29.98 & 0.13 & 25.33 & 23.95 \\
\hline Native public enrollment per 100 households & 19.67 & 19.46 & 15.42 & 25.00 & 0.14 & 17.05 & 17.87 \\
\hline Share natives in public schools & 64.67 & 64.37 & 58.56 & 69.32 & 0.04 & 63.35 & 65.68 \\
\hline Implicit tax rate $(\%)$ & 5.93 & 5.96 & 5.42 & 6.38 & 0.05 & 6.13 & 5.76 \\
\hline Public educ. spending per student (euros) & 4,582 & 4,712 & 3,070 & 6,235 & 0.20 & 5,069 & 5,788 \\
\hline \multicolumn{8}{|l|}{ Immigration (benchmark - counterfactual) } \\
\hline Public enrollment per 100 households & 1.27 & 1.27 & 0.23 & 3.54 & 0.72 & 2.11 & 1.64 \\
\hline Native public enrollment per 100 households & -2.84 & -2.63 & -5.51 & -0.62 & -0.54 & -3.48 & -3.52 \\
\hline Share natives in public schools (pp) & 0.76 & 0.86 & -0.41 & 3.08 & 1.10 & 1.63 & 0.80 \\
\hline Implicit tax rate $(\%)$ & -0.64 & -0.75 & -2.81 & 0.94 & -1.19 & -1.73 & -0.85 \\
\hline Public educ. spending per student (\%) & 3.17 & 3.58 & -1.66 & 12.58 & 1.09 & 6.80 & 3.32 \\
\hline \multicolumn{8}{|l|}{ Naturalization (counterfactual - benchmark) } \\
\hline Public enrollment per 100 households & -0.63 & -0.68 & -1.37 & -0.16 & -0.56 & -0.94 & -0.79 \\
\hline Native public enrollment per 100 households & -0.65 & -0.59 & -1.05 & -0.15 & -0.51 & -0.76 & -0.67 \\
\hline Share natives in public schools (pp) & -2.13 & -1.96 & -3.71 & -0.45 & -0.51 & -2.81 & -2.48 \\
\hline Implicit tax rate $(\%)$ & -7.36 & -6.90 & -12.38 & -1.62 & -0.48 & -9.76 & -8.85 \\
\hline Public educ. spending per student (\%) & -7.68 & -6.90 & -12.38 & -1.62 & -0.48 & -9.76 & -8.85 \\
\hline \multicolumn{8}{|l|}{ Combined effect (Naturaliz. - Immig. 2000) } \\
\hline Public enrollment per 100 households & 0.63 & -0.25 & -0.70 & 2.17 & 1.17 & 1.17 & 0.85 \\
\hline Native public enrollment per 100 households & -3.49 & -2.56 & -6.56 & -0.80 & -0.53 & -4.23 & -4.20 \\
\hline Share natives in public schools (pp) & -2.89 & -1.12 & -6.72 & -0.74 & -0.62 & -4.44 & -3.28 \\
\hline Implicit tax rate $(\%)$ & -6.72 & -5.81 & -11.12 & 0.35 & -0.56 & -8.02 & -8.00 \\
\hline Public educ. spending per student (\%) & -10.85 & -4.00 & -24.84 & -2.79 & -0.61 & -16.56 & -12.17 \\
\hline
\end{tabular}

Notes: The first column reports the data and counterfactual values for Spain as a whole. It has already been reported in the previous tables but it is included here to facilitate comparisons. Column 2 reports the simple average of each variable across all 17 regions (autonomous communities). Columns 3 and 4 report the minimum and maximum values. Column 5 is the coefficient of variation. Columns 6 and 7 , respectively, report the values for the regions of Catalonia and Madrid. 
Figure 1: Percentage change in the student-teacher ratio between 2000 and 2010 against the change in the foreign-born share in the region.

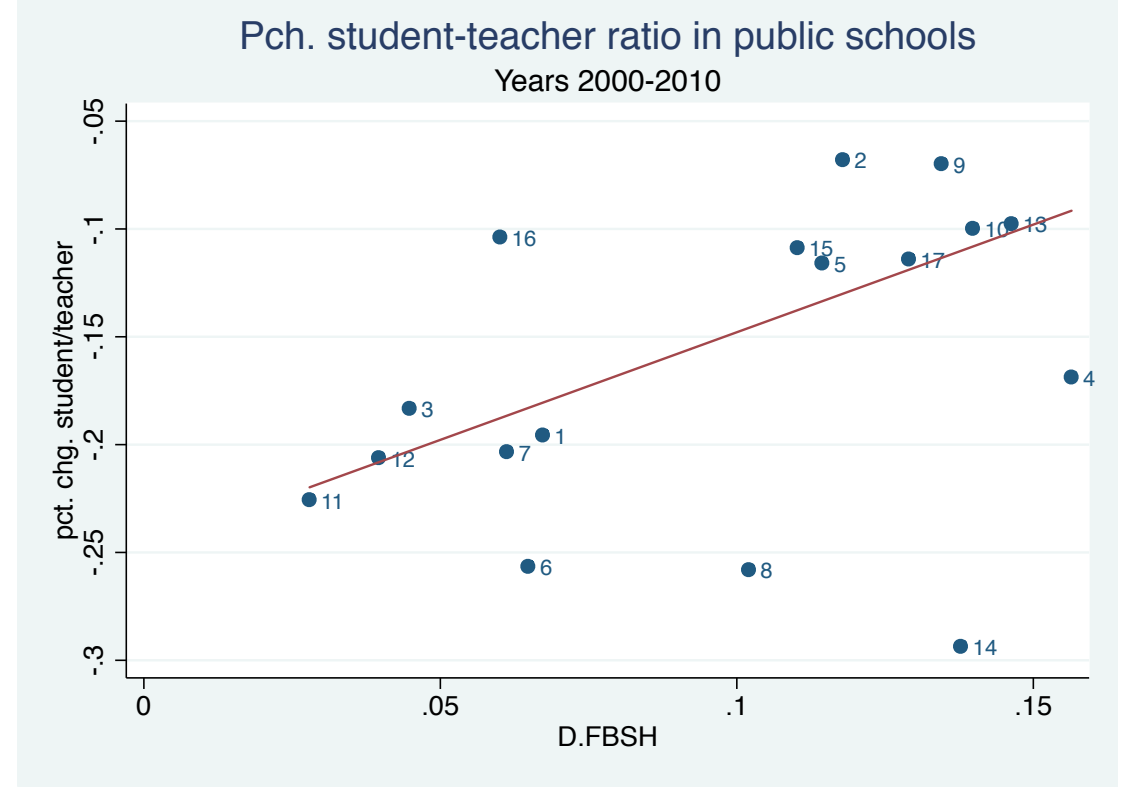

Notes: In linear regression fit each region is weighted by its year-2000 population. Next we list all regions (autonomous communities) and their numerical code: Andalucia (1), Aragon (2), Asturias (3), Balearic Islands (4), Canary Islands (5), Cantabria (6), Castilla Leon (7), Castilla La Mancha (8), Catalonia (9), Valencia (10), Extremadura (11), Galicia (12), Madrid (13), Murcia (14), Navarra (15), Basque Country (16), La Rioja (17). 
Figure 2: Combined effect on public education expenditure per student

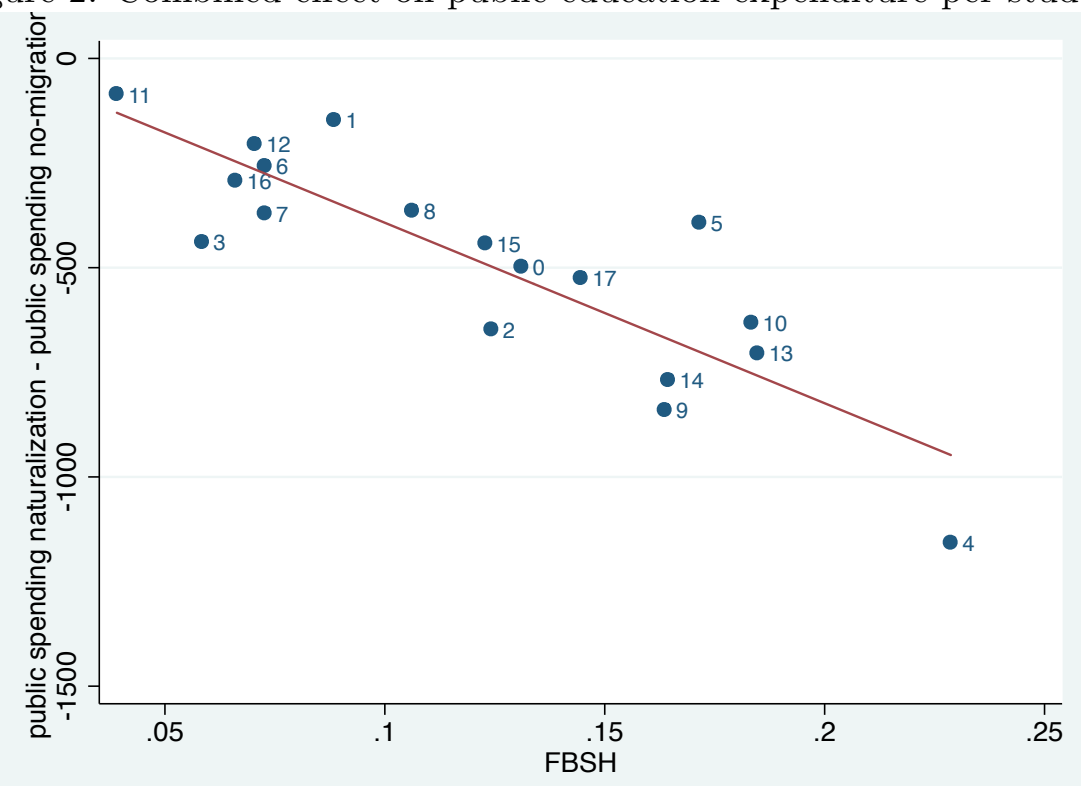

Notes: Slope coefficient is -4313.56 , with t-stat of -6.57 .

Figure 3: Immigration and Native flight to private schools

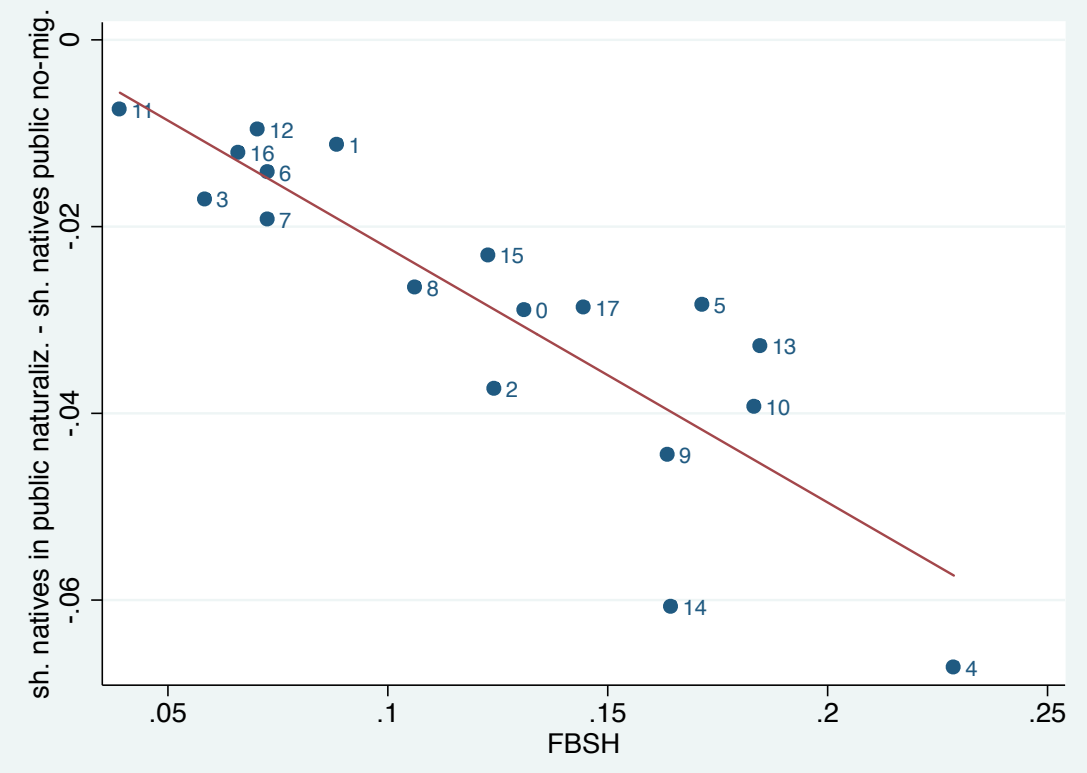

Notes: Slope coefficient is -0.27 , with t-stat of -6.89 . The vertical axis reports the share of native children enrolled in private schools in the naturalization scenario minus the same variable in the scenario where each region's immigrant population is as in year 2000 . 
Figure 4: Policy convergence: the implicit tax rate

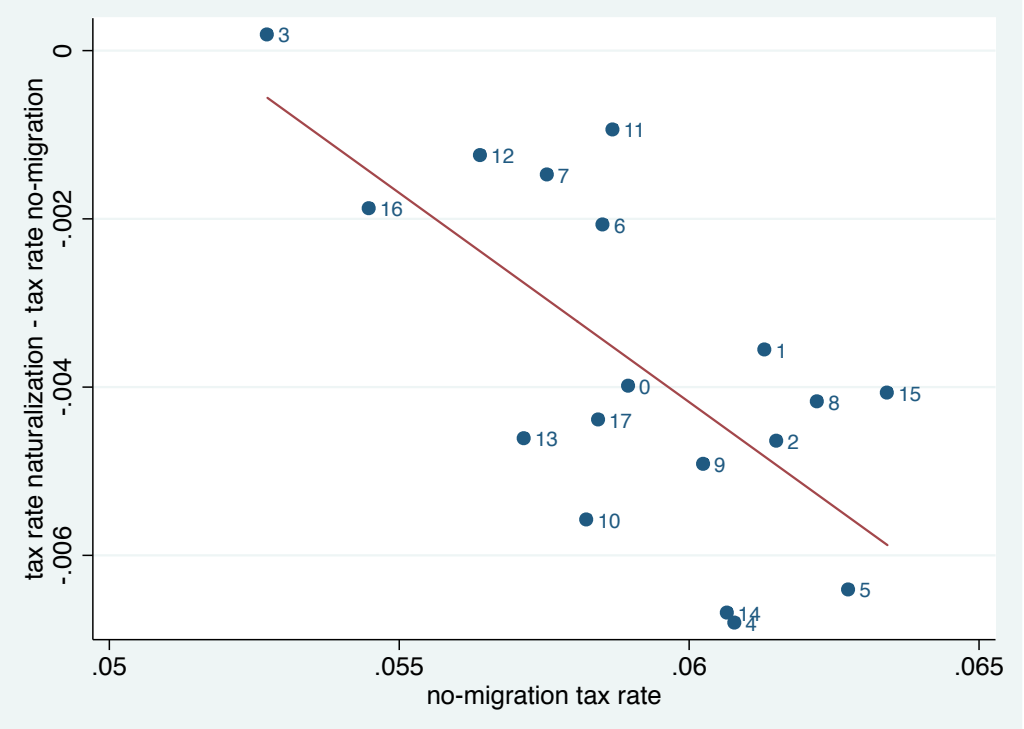

Notes: The estimated slope coefficient is -0.50 , with t-stat of -3.69 . Next we list all regions (autonomous communities) and their numerical code: Andalucia (1), Aragon (2), Asturias (3), Balearic Islands (4), Canary Islands (5), Cantabria (6), Castilla Leon (7), Castilla La Mancha (8), Catalonia (9), Valencia (10), Extremadura (11), Galicia (12), Madrid (13), Murcia (14), Navarra (15), Basque Country (16), La Rioja (17).

Figure 5: Policy convergence: public education expenditure per student

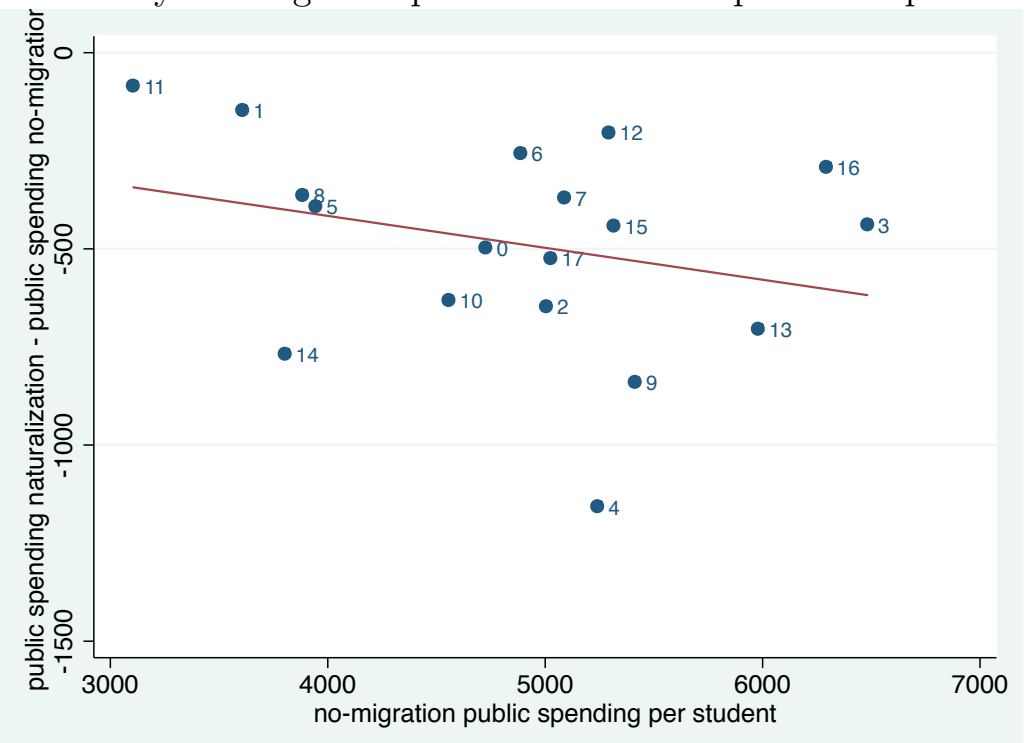

Notes: The estimated slope coefficient is -0.08 , with t-stat of -1.16 . 


\section{Appendices}

\section{A Data appendix}

In this appendix, we provide further detail on the data sources and the construction of our variables.

The number of households in each group (Labor force Survey), enrollment by type of school (Ministry of Education), the income distribution at the household level (Family Expenditure Survey and National Immigrant Survey), and public spending in education (Ministry of Education).

The Family Expenditure Survey (hereafter FES) contains income data but only identifies immigrant households from year 2006 onward. In addition, the level of disaggregation of the immigrant population is very limited. To overcome this limitation we also use the 2007 National Immigrant Survey to compute household income for each immigrant group. We provide more detail in Appendix B.

\section{A.1 Household distribution}

The distribution of households is estimated on the basis of the micro-data from the Spanish Labor Force Survey using the appropriate weights. We only include households headed by individuals age 65 or younger.

\section{A.2 Income distribution}

Our primary source of information for income distributions is the Family Expenditure Survey (FES). This survey reports monthly household income, which includes labor income, capital income, and government cash benefits. To produce an annual value we multiplied monthly income by 14 to take into account double the widespread double-pay in August and December. Prior to year 2006 the FES did not identify immigrant households. From 2006 onward it includes a variable reporting on the nationality of the household head. However, this variable provides very little disaggregation of the immigrant population. Thus we use the 2007 National Immigrant Survey (NIS) to compute the average and standard deviation of household income for each of our four immigrant groups (European, American, African and Asian) by the number of children in the household. Since it only surveyed the immigrant population, the NIS did not provide information on the native population. One additional difference between the two surveys is that the FES reports household income whereas the NIS reports the income of one individual chosen randomly in each household and thus does not always correspond to the household head. We make some adjustments to the NIS data to make it more consistent with the income data in the FES. The details of our imputation are reported inAppendix B.

\section{A.3 The share of public and private school students}

Our model is tailored to compulsory education. Thus it is natural to focus on enrollment in primary and secondary education. Specifically, our enrollment variables include the following education levels: preschool, elementary, compulsory secondary education (known as E.S.O. in Spanish), non-compulsory secondary education (both the so-called 'bachillerato' and occupational training i.e. 'formation profesional'), and special education. The enrollment data are provided by the Ministry of Education and made publicly available on their website. ${ }^{58}$

\footnotetext{
${ }^{58}$ http://www.mecd.gob.es/horizontales/estadisticas/no-universitaria.html. Specifically, the files referring to pre-university education studies, 'Alumnado. Regimen General'.
} 
Breakdown of Foreign Student Population by Continent of Origin is available only for all school levels together (infantil, primary, secondary part1, secondary part2, bachillerato and FP). Disaggregation of the data by levels is not available in the Ministerio Tables. We know that primary+ESO accounted for 68.76 percent of the total enrollment of foreign students in 2008. Since breakdown by origins is unavailable, we use this information to map total enrollment of foreigners into total enrollment in primary+ESO. We are ignoring that this rate may apply differently to different immigrant groups.

Throughout our paper private schools refer to the sum of subsidized (concerted) private schools and non-subsidized private schools. The number of students in public schools for each group $m$ in the column 1 of the Table 3 is estimated using the data of total number of children and the actual share of public school students for each group $m$. Specifically, the household distribution $h^{t}(n, m)$ and the total number of household provide the total number of children for each $m$, and the number of public school students is obtained from this total number of children multiplied by the actual share of public school enrollment for each $m$ provided by provided by the Ministry of Education. This adjustment is important to make it consistent with the overall number of children implied by our household distribution and the share of public (and private) school students in the model.

\section{A.4 Education expenditure}

The information on public spending in education is obtained from the Statistics on Public Education Expenditure produced by the Ministry of Education. We report spending for the pre-university education levels: preschool, elementary, compulsory secondary education (known as E.S.O. in Spanish), non-compulsory secondary education (both the so-called 'bachillerato' and occupational training i.e. 'formation profesional'), and special education.

\section{B Imputation of income distributions}

For our calibration and simulation exercises we need to obtain income distributions for each population group ( $m=0$ for natives, 1 for European immigrants, 2 for African immigrants, 3 for American immigrants, and 4 for immigrants from Asia and Oceania.

We firstly calculate the mean and the coefficient of variation of household income, conditional on number of children and on immigration status from NIS. Secondly we calculate the average income for immigrants from the FES. This is the average income of all immigrants, so we want to disaggregate it for each immigration status (i.e., $m=1,2,3$, and 4). ${ }^{59}$ Note that there is the following relationship between the average income from the FES and the mean income from the NIS:

$$
\bar{y}_{i m m}=\frac{1}{h_{1}+h_{2}+h_{3}+h_{4}} \sum_{m=1}^{4} h_{m} \bar{y}_{m}
$$

where $\bar{y}_{i m m}$ is the average income of all immigrants calculated from the FES, $h_{m}$ is the number of households with immigration status $m$, and $\bar{y}_{m}$ is the average income of type $m$ households calculated from the NIS.

However, we suspect that our measure of household income based on the NIS is an underestimate. Hence we estimate the mean income consistent with the relative income among the four types of immigrants as follows. Let $\hat{y}_{m}$ denote the estimate of mean household income of immigrants with type $m$. We impose a condition that $\hat{y}_{m}$ relative to any other mean income is consistent with the relative mean income from the NIS:

$$
\frac{\hat{y}_{m}}{\hat{y}_{n}}=\frac{\bar{y}_{m}}{\hat{y}_{n}}
$$

\footnotetext{
${ }^{59}$ Income distribution for natives can be calculated directly from the FES.
} 
for all $m$ and $n$. Without loss of generality, set $n=1$. Replacing $\bar{y}_{m}$ with $\hat{y}_{m}$ in this equation, we obtain the following expression:

$$
\bar{y}_{i m m}=\frac{1}{h_{1}+h_{2}+h_{3}+h_{4}} \sum_{m=1}^{4} h_{m} \hat{y}_{m}=\frac{1}{h_{1}+h_{2}+h_{3}+h_{4}} \sum_{m=1}^{4}\left(h_{m} \frac{\bar{y}_{m}}{\bar{y}_{1}}\right) \hat{y}_{1} .
$$

Hence we obtain

$$
\begin{gathered}
\hat{y}_{1}=\bar{y}_{i m m}\left(\frac{1}{h_{1}+h_{2}+h_{3}+h_{4}} \sum_{m=1}^{4}\left(h_{m} \frac{\bar{y}_{m}}{\bar{y}_{1}}\right)\right)^{-1}, \\
\hat{y}_{m}=\frac{\bar{y}_{m}}{\bar{y}_{1}} \hat{y}_{1}
\end{gathered}
$$

for $m=1,2,3,4$. These estimates of mean income for each $m$ generate weighted mean income consistent with that from the FES.

The standard deviation of household income for each $\mathrm{m}$ is estimated using the coefficient of variation. Let $\hat{\sigma}_{m}$ denote an estimate of standard deviation of household income with type $m$. We obtain this estimate by:

$$
\hat{\sigma}_{m}=c v_{m} \hat{y}_{m}
$$

for $m=1,2,3,4$ where $c v_{m}$ is the coefficient of variation for type $m$ calculated from the NIS.

We impute income distributions for each region using the same method described above. In the imputation of regional income distribution, we allow regional variation of average household income for natives and immigrants, but we impose the two conditions that the coefficient of variations are same for all regions, and that relative mean income among immigration status is constant across regions.

\section{B.1 Alternative measure of spending per student in public schools}

In our tables we report the 'actual' public education spending per student (for pre-university education, that is, pre-school, elementary, secondary and special education). This is the overall public spending in pre-university education (including the subsidy to concerted schools) over the enrollment in public schools plus the enrollment in concerted schools. Note that the denominator includes all students that receive public financing, either directly because they attend public schools or indirectly through the subsidy received by their private schools.

Alternatively, we can report the actual spending per student in public schools, where the numerator includes only spending directly used to finance public schools (thus excluding the subsidy to private schools) and the denominator is the enrollment in public schools. This figure is always larger because the data shows that the subsidy per student is lower than the spending per student in public schools. The table below summarizes these variables for year 2008. 
Table B.1: Public spending per student. Pre-university levels.

\begin{tabular}{lccc}
\hline \hline & & & \\
Year 2008 (pre-uni.) & Overall & Public schools & Concerted \\
& & & \\
\hline & & & \\
Public spending ( $10^{9}$ of euros) & 31.13 & 25.71 & 5.42 \\
Enrollment $\left(10^{6}\right.$ students) & 6.95 & 5.01 & 1.95 \\
Public spending / Enrollment (euros) & 4,475 & 5,133 & 2,783 \\
& & & \\
\hline \hline
\end{tabular}

Notes: Sistema Estatal de Indicadores de la Educacion, 2012, and Enrollment general regime data. Preuniversity education includes pre-school, elementary, secondary, and special education. 